\title{
Frequency-Dependent Modes of Synaptic Vesicle Endocytosis and Exocytosis at Adult Mouse Neuromuscular Junctions
}

\author{
Yuka Maeno-Hikichi, Luis Polo-Parada, Ksenia V. Kastanenka, and Lynn T. Landmesser \\ Department of Neurosciences, Case Western Reserve University School of Medicine, Cleveland, Ohio 44106-4975
}

\begin{abstract}
During locomotion, adult rodent lumbar motoneurons fire in high-frequency $(80-100 \mathrm{~Hz}) 1-2 \mathrm{~s}$ bursts every several seconds, releasing between 10,000 and 20,000 vesicles per burst. The estimated total vesicle pool size indicates that all vesicles would be used within $30 \mathrm{~s}$; thus, a mechanism for rapid endocytosis and vesicle recycling is necessary to maintain effective transmission and motor behavior. However, whether such rapid recycling exists at mouse neuromuscular junctions (NMJs) or how it is regulated has been unclear. Here, we show that much less FM1-43 dye is lost per stimulus with $100 \mathrm{~Hz}$ stimulation than with $10 \mathrm{~Hz}$ stimulation even when the same number of vesicles undergo exocytosis. Electrophysiological data using folimycin show this lesser amount of dye loss is caused in part by the rapid reuse of vesicles. We showed previously that a myosin light chain kinase (MLCK)-myosin II pathway was required for effective transmission at $100 \mathrm{~Hz}$. Here, we confirm the activation of MLCK, based on increased nerve terminal phospho-MLC immunostaining, with 100 $\mathrm{Hz}$ but not with $10 \mathrm{~Hz}$ stimulation. We further demonstrate that activation of MLCK, by increased extracellular $\mathrm{Ca}^{2+}$, by PKC (protein kinase C) activation, or by a MLCK agonist peptide, reduces the amount of dye lost even with $10 \mathrm{~Hz}$ stimulation. MLCK activation at $10 \mathrm{~Hz}$ also resulted in more vesicles being rapidly reused. Thus, MLCK activation by $100 \mathrm{~Hz}$ stimulation switches the mechanism of vesicle cycling to a rapid-reuse mode and is required to sustain effective transmission in adult mouse NMJs.
\end{abstract}

\section{Introduction}

The adult vertebrate neuromuscular junction (NMJ) is a highly reliable synapse that must exocytose a large number of vesicles with each stimulus to ensure effective excitation of the postsynaptic muscle fiber. During normal locomotor movements, most motoneurons are activated for only brief periods $(1-2 s)$ with similar duration intervening periods of rest. In addition, fast rat motoneurons fire in vivo at frequencies of between 80 and $100 \mathrm{~Hz}$ with even higher frequencies at the beginning of bursts (Gorassini et al., 2000). Since the quantal content of the mouse fast semitendinosus junctions used in the present study is $\sim 100$ (Polo-Parada et al., 2001), a 1 s $100 \mathrm{~Hz}$ burst, which mimics in vivo locomotor activity, would trigger the release of $\sim 10,000$ vesicles. To maintain effective synaptic transmission, the NMJ must be able to resupply an equivalent number of vesicles by subsequent endocytosis or by recruitment from the reserve pool. Since the size of

\footnotetext{
Received June 2, 2010; revised Sept. 27, 2010; accepted Nov. 9, 2010.

This work was supported by National Institutes of Health-National Institute of Neurological Disorders and Stroke Grants NS19640 and NS23678 (L.T.L.) and by American Heart Association Grant 0530140 (L.P.-P.). We thank Katherine Lobur and Smaranda Ene for their excellent technical assistance and Katsusuke Hata and Sheng Wang for their input throughout this work. We also thank Guillermo Pilar, David Friel, and Corey Smith for their comments on this manuscript. The mAb 35 developed by J. Lindstrom was obtained from the Developmental Studies Hybridoma Bank developed under the auspices of the National Institute of Child Health and Human Development and maintained by Department of Biology, University of lowa (lowa City, IA).

Correspondence should be addressed to Lynn T. Landmesser, Department of Neurosciences, Case Western Reserve University, 10900 Euclid Avenue, Cleveland, 0H 44106-4975. E-mail: lynn.landmesser@case.edu.

L. Polo-Parada's present address: Department of Medical Pharmacology and Physiology, Dalton Cardiovascular Research Center, University of Missouri, 134 Research Park Drive, Columbia, M0 65211.

DOI:10.1523/JNEUROSCI.2800-10.2011

Copyright $\odot 2011$ the authors $\quad 0270-6474 / 11 / 311093-13 \$ 15.00 / 0$
}

the total pool of synaptic vesicles (sum of reserve pool, recycling pool, and readily releasable pool) at rodent NMJs has been estimated to be between 174,000 and 366,000 (Elmqvist and Quastel, 1965; Schofield and Marshall, 1980; Reid et al., 1999), in the absence of a mechanism for replenishment, at release rates needed to sustain transmission during in vivo locomotion, all vesicles would be used within $\sim 1 \mathrm{~min}$. Therefore, a mechanism for very rapid vesicle recycling must exist to maintain effective transmission when terminals are activated with high-frequency repetitive stimulation. We previously identified an intracellular signaling pathway involving myosin light chain kinase (MLCK) and myosin II as being required for effective transmission at adult mouse NMJs at high $(100 \mathrm{~Hz}$ and above) but not at low $(10 \mathrm{~Hz})$ stimulus frequencies (PoloParada et al., 2001, 2004, 2005). When this pathway is blocked, the junctions are activated normally at $10 \mathrm{~Hz}$, but they exhibit cyclical periods of transmission failures at $100 \mathrm{~Hz}$ (PoloParada et al., 2001, 2004, 2005). Thus, it appears that the junctions are normally able to switch from a mode of transmission that does not require the MLCK pathway to one that does, depending on the frequency of stimulation. To further explore the distinctive mechanisms of vesicle cycling used at each frequency and the signal(s) that might trigger the switch in cycling mechanisms, we studied adult mouse NMJs by electrophysiology and by using styryl dyes (Betz et al., 1992, 1996; Cousin and Robinson, 1999; Ryan, 2001; Gaffield and Betz, 2006) to assess the synaptic vesicle exocytosis and endocytosis under different conditions. 


\section{Materials and Methods}

Tissue preparation. All experiments were performed according to protocols approved by the Institutional Animal Care and Use Committee of Case Western Reserve University, an accredited oversight body (Federal Animal Welfare Assurance No. A3145-01), in accordance with National Institutes of Health guidelines. Semitendinosus muscles with attached nerves were dissected from 1- to 2-month-old adult C57BL/6 mice (inbred; originally from The Jackson Laboratory). Animals were killed by carbon dioxide and decapitated. Muscles were immediately removed and immersed in ice-cold Tyrode's solution [ $125 \mathrm{~mm} \mathrm{NaCl}, 5 \mathrm{~mm} \mathrm{KCl}, 24 \mathrm{~mm}$ $\mathrm{NaHCO}_{3}, 1 \mathrm{~mm} \mathrm{MgCl}, 10 \mathrm{~mm}$ glucose (Sigma-Aldrich), $2 \mathrm{~mm} \mathrm{CaCl}$ ] that was oxygenated by $95 \% \mathrm{O}_{2}-5 \% \mathrm{CO}_{2}$ (all chemicals were from Thermo Fisher Scientific, unless otherwise noted). Muscles were cleaned by removing excess fat and connective tissue and then kept in oxygenated Tyrode's until needed.

Peptide introduction into adult NMJs. Peptides were introduced into the semitendinosus nerve-muscle preparation by using the peptide carrier Chariot (Active Motif) according to the manufacturer's instructions. Briefly, a Chariot stock solution $(2 \mathrm{mg} / \mathrm{ml})$ was prepared, aliquoted, and kept at $-70^{\circ} \mathrm{C}$. The frozen stock solution was thawed and sonicated 3 min in a water bath and mixed with the peptide solution at a peptide/ chariot mole ratio of 1:4 and incubated at room temperature for $1 \mathrm{~h}$. The final peptide concentration in the bath was adjusted to $3.5 \mu \mathrm{M}$. The sequences of peptides used are KKDRMKKYMA (synthesized by the Analysis Department, Wolfson Institute for Biomedical Research, London, UK) for the MLCK agonist peptide and EAVSLKPT (Calbiochem) for the protein kinase $\mathrm{C} \varepsilon(\mathrm{PKC} \varepsilon)$ translocation inhibitor peptide.

Electrophysiological recordings. Electrophysiological recordings were conducted using standard methods from acutely isolated semitendinosus muscles as described previously (Polo-Parada et al., 2005). The musclenerve preparation was gently extended and pinned flat in a Sylgard (Dow Corning)-coated recording chamber, perfused with normal Tyrode's solution, and gassed with $95 \% \mathrm{O}_{2}-5 \% \mathrm{CO}_{2}$. To prevent muscle contraction, 1-2 $\mu \mathrm{M} \mu$-conotoxin GIIIB (muscle-specific voltage-gated sodium channel blocker) (Alomone Labs) was added to the perfusion buffer. Sharp glass electrodes were pulled (10-20 M $\Omega$ ), filled with $3 \mathrm{M} \mathrm{KCl}$, and single muscle fibers were impaled near the motor endplate. Potentials were recorded via an intracellular amplifier (World Precision Instruments) using Axoscope software (40 kHz sampling rate; Applied Biosystems/MDS Analytical Technologies). The nerves were stimulated via a suction electrode pulled from polyethylene tubing (PE-190; BD Biosciences) and a SQ38 stimulator and PSIU6B stimulus isolation unit (Grass Technologies). The MLCK agonist peptide or the PKC $\varepsilon$ translocation inhibitor peptide was introduced into the bath $1 \mathrm{~h}$ before and was kept in the bath during the recordings. Folimycin (EMD Chemicals; final concentration of $160 \mathrm{~nm}$ ) was added to the bath 1 min before the recordings and kept in the bath throughout the recordings. Recordings were made within $30 \mathrm{~min}$ after applying the folimycin to prevent the drug from affecting vesicles that had not undergone exocytosis. Eighty micromolar dynasore (Sigma-Aldrich) was used to block dynamin 1 and 2 activity, and was applied $30 \mathrm{~min}$ before and throughout the recordings.

Immunohistochemistry. Semitendinosus muscles were dissected and quickly fixed in $3.7 \%$ formaldehyde (Sigma-Aldrich) in PBS (140 mM $\mathrm{NaCl}, 2.7 \mathrm{~mm} \mathrm{KCl}, 10 \mathrm{mM} \mathrm{Na}_{2} \mathrm{HPO}_{4}, 1.8 \mathrm{mM} \mathrm{KH}_{2} \mathrm{PO}_{4}$ ) at room temperature for $30 \mathrm{~min}$, washed with PBS, and cryoprotected in $30 \%$ sucrose in PBS overnight at $4^{\circ} \mathrm{C}$. Fifty micrometer longitudinal frozen sections or 12 $\mu \mathrm{m}$ cross-sections were cut, mounted on gelatin-coated slides, air-dried, and stored at $-70^{\circ} \mathrm{C}$. Sections were permeabilized and blocked with $2 \%$ bovine serum albumin (Sigma-Aldrich), 10\% goat serum, and 0.5\% Triton X-100 in PBS at room temperature for $1 \mathrm{~h}$, then incubated with primary antibodies at either room temperature for $2 \mathrm{~h}$ or at $4^{\circ} \mathrm{C}$ overnight, washed, and then incubated at room temperature for $2 \mathrm{~h}$ with fluorochrome-conjugated secondary antibodies (Zymed) and with fluorochrome-conjugated $\alpha$-bungarotoxin (Invitrogen) to visualize the postsynaptic acetylcholine receptors. The primary antibodies used were phospho-MLC2 (T18/S19) (Cell Signaling Technology) and PKC $\varepsilon$ (Santa Cruz). For the phorbol 12-myristate 13-acetate (PMA) treatment, 100 nм PMA (Sigma-Aldrich) was added to the bath for 1 min before rapid fixation of the muscle. Stimulated samples were prepared either by stimulating the nerve-muscle preparation at $10 \mathrm{~Hz}$ for $10 \mathrm{~min}$ or at 100 $\mathrm{Hz}$ for $1 \mathrm{~min}$ and replacing the Tyrode's solution with $3.7 \%$ formaldehyde in PBS 30 s before the end of stimulation, followed by an additional $30 \mathrm{~min}$ fixation. For peptide treatment, muscles were preincubated with the peptide-Chariot complex for $1 \mathrm{~h}$ and then stimulated at either 10 or $100 \mathrm{~Hz}$. To prevent dephosphorylation, a phosphatase inhibitor tablet, PhosSTOP (Roche), was added to the fixing solution.

Quantification of immunohistochemistry. After immunostaining, pictures were acquired with a BX51WI Olympus microscope or a Nikon Microphoto-FX (Nikon Instruments) equipped with Retiga EXi CCD camera (QImaging) using the same exposure time between samples. Quantification of pixel intensity was performed with the MetaMorph Imaging System (Molecular Devices) on defined regions of interest using the same parameters between samples. Background nonspecific muscle staining/autofluorescence was subtracted from each picture by using the same sized region of interest and an area adjacent to the endplate on the same muscle.

FM dye optical imaging. The nerve-muscle preparation was pinned flat in a Sylgard-coated recording chamber, perfused with normal Tyrode's solution, and gassed with $95 \% \mathrm{O}_{2}-5 \% \mathrm{CO}_{2}$. Endplates were labeled with the nicotinic acetylcholine receptor antibody mAb 35 (Developmental Studies Hybridoma Bank) conjugated with Alexa 546 fluorochrome (Invitrogen) for $1 \mathrm{~h}$ together with $\mu$-conotoxin GIIIB to block contractility. The recycling pool of synaptic vesicles was loaded with either FM1-43 or FM2-10 (both from Invitrogen) by stimulating the nerve at either $10 \mathrm{~Hz}$ for $30 \mathrm{~min}$ or $100 \mathrm{~Hz}$ for $3 \mathrm{~min}$ in normal Tyrode's solution with $8 \mu \mathrm{M}$ FM1-43 or $100 \mu \mathrm{M}$ FM2-10. Some short-term stimulation protocols used either $10 \mathrm{~Hz}$ for $10 \mathrm{~min}$ or $100 \mathrm{~Hz}$ for $1 \mathrm{~min}$. The muscles were incubated in the FM dye for 5 min after the stimulus to allow any slow endocytosis to be completed. The sample was then washed with low-calcium, highmagnesium Tyrode's three times, incubated with ADVASEP-7 (Biotium) for $5 \mathrm{~min}$, washed again, and perfused at least $20 \mathrm{~min}$ with low-calcium high-magnesium Tyrode's. To unload FM dye, the bath solution was replaced with normal calcium Tyrode's and perfused for 5-10 min, and then stimulated at either 10 or $100 \mathrm{~Hz}$. The MLCK agonist peptide was added after complete loading and washing as described above during a $1 \mathrm{~h}$ incubation. The buffer was replaced with normal Tyrode's before dye destaining. To see the effect of PMA on FM destaining, 100 nM PMA was added to the bath before the destaining stimulation and when the buffer was replaced with normal Tyrode's with drug. PMA was kept in the buffer during the destaining stimulation. To see effects of different drugs on loading at $100 \mathrm{~Hz}$, nifedipine (final concentration of $5 \mu \mathrm{M})$ or BFA (10 $\mu \mathrm{g} / \mathrm{ml}$ ) were added into the bath for $1 \mathrm{~h}$ preincubation before the loading. Botulinum neurotoxin A (BoNTXA) was activated with 5 mм DTT for $1 \mathrm{~h}$, and then added to the bath for a final concentration of $5 \mathrm{~nm} 3 \mathrm{~h}$ before the start of loading.

Data presentation and analysis. All data are presented as mean $\pm \mathrm{SE}$. The statistical significance was calculated by one-way ANOVA unless noted otherwise and is presented as ${ }^{* *} p<0.01$ or ${ }^{\star} p<0.05$. In many experiments, $n$ refers to the number of separate experiments and is presented as $N_{\exp }(N=$ number of experiments). In other cases, in which multiple endplates were assessed in one or more muscles, $n$ is also presented as $n_{\text {end }}(n=$ number of endplates).

\section{Results}

Characteristics of endocytosis at adult mouse neuromuscular junctions with $10 \mathrm{~Hz}$ stimulation

Sustained effective transmission relies on a balance between exocytosis and endocytosis and the speed of synaptic vesicle recycling. To examine these different components, we monitored the FM dye uptake and destaining at adult mouse NMJs. Since FM dye destaining will, in part, be based on the behavior of the pool of vesicles previously loaded with dye, we first examined dye uptake with $10 \mathrm{~Hz}$ stimulation. To mimic the physiological condition, we used a series of $1 \mathrm{~s}$ trains at $10 \mathrm{~Hz}$ with intervening $1 \mathrm{~s}$ rest periods $(1 \mathrm{~s}$ trains at $0.5 \mathrm{~Hz}$ ) (Fig. $1 \mathrm{~A}$ ). Although both exocytosis and endocytosis occur during the stimulation period, en- 


\section{A FM dye loading protocol}

\section{FM dye loading}

During stimulation

Stimulation

Time
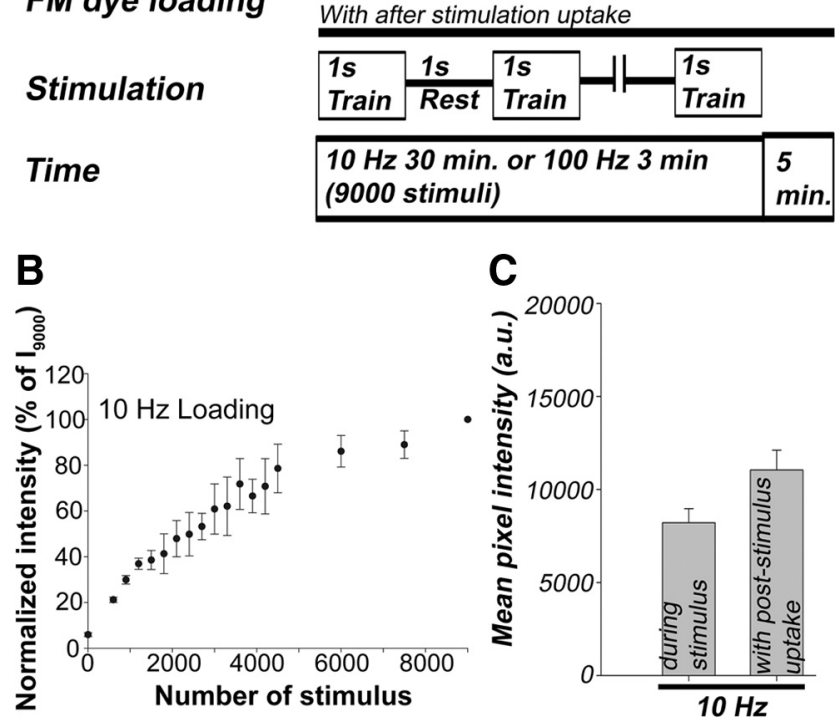

Figure 1. FM1-43 uptake at the adult mouse neuromuscular junction. $\boldsymbol{A}$, Schematic diagram of the stimulation and FM dye loading protocol. $B, F M 1-43$ uptake with a $10 \mathrm{~Hz}, 30$ min stimulation. The error bars indicate SE throughout the study $\left(n_{\text {end }}=17 ; N_{\text {exp }}=17\right)$. C, A bar graph of final pixel intensity after completion of uptake when dye was present only during the stimulus or for an additional $5 \mathrm{~min}$ after the end of the stimulus. Endpoint pixel intensity was measured after washing out nonspecific binding of FMs on the surface membrane and thus reflects only internalized FMs. Mean values at $10 \mathrm{~Hz}$ were $8208 \pm 759\left(n_{\text {end }}=30 ; N_{\exp }=2\right)$ and 11,044 \pm $1062\left(n_{\text {end }}=63 ; N_{\exp }=15\right)$ for loading only during the stimulus or with 5 min poststimulus dye incubation, respectively. Statistical significance was indicated throughout the study as follows: ${ }^{* *} p<0.01$ or ${ }^{*} p<0.05$.

docytosis can continue after the end of stimulation (de Lange et al., 2003; Royle and Lagnado, 2003), especially in cases in which the endocytic process is not rapid enough to retrieve all the vesicle membrane added to the terminal surface membrane during the stimulus period. Therefore, we compared dye uptake when FM1-43 was in the bath only during the period of the 9000 stimuli (Fig. $1 A, B$ ) and when the dye remained in the bath for 5 min after stimulus termination (Fig. $1 A, C$ ). In experiments in which dye uptake was measured while FM dye was still in the bath (Figs. $1 B$, $4 A$ ), the amount of uptake will include both dye taken into vesicles and cell surface labeling. However, for simplicity, we refer to this simply as "uptake." To characterize the frequency dependence, we plotted dye uptake or loss per stimulus event and not as a function of time throughout this work, and related the change in dye uptake or loss to the number of vesicles exocytosed, based on summed quantal content.

When NMJs were loaded with FM1-43 by $10 \mathrm{~Hz}$ stimulation, dye uptake occurred in an asymptotic manner and reached a plateau after $\sim 15 \min (4000-6000$ stimuli) (Fig. $1 B$ ). At $10 \mathrm{~Hz}$ stimulation, a slight increase of dye uptake was also observed after stimulus cessation (Fig. 1C). The mean intensity values after wash, which will remove surface labeling, were $8208 \pm 759\left(n_{\text {end }}=30\right.$; $\left.N_{\exp }=2\right)$ at the end of $30 \mathrm{~min}$ of stimulation, with an additional increase to $11,044 \pm 1062\left(n_{\text {end }}=63 ; N_{\exp }=15\right)$ after a 5 min poststimulus loading period. Although the mean intensity increased by $2836 \pm 1821$ ( $26 \%$ of the total dye) after stimulus cessation, the total mean intensity at the end of loading period did not differ significantly from that at the end of stimulation $(p>$ 0.05 ). Thus, most of the endocytosis triggered by $10 \mathrm{~Hz}$ stimulation is completed during the stimulation period.
The amount of FM1-43 dye loss differs at 10 and $100 \mathrm{~Hz}$ even for the same number of vesicles undergoing exocytosis

To examine the process of exocytosis at different frequencies of stimulation, we characterized the amount of dye loss from vesicle pools that were loaded with $10 \mathrm{~Hz}$ stimulation. To maximize dye loading into all releasable vesicle pools, unless noted otherwise, our standard loading protocol was $10 \mathrm{~Hz}$ stimulation for $30 \mathrm{~min}$ (1 s $10 \mathrm{~Hz}$ trains at $0.5 \mathrm{~Hz} ; 9000$ stimuli) with dye remaining in the bath for an additional $5 \mathrm{~min}$ (Fig. $1 A$ ). After a wash in low$\mathrm{Ca}^{2+}$ Tyrode's solution with ADVASEP-7 to remove any cell surface label, the amount of dye loss from the loaded vesicles was assessed by stimulating the endplates with $1 \mathrm{~s}$ trains of either 10 or $100 \mathrm{~Hz}$, with $1 \mathrm{~s}$ alternating periods of rest, a pattern that approximates the way in which these junctions would be activated in vivo (Gorassini et al., 2000) (Fig. 1A).

At $10 \mathrm{~Hz}$, dye loss was rapid with $\sim 50 \%$ of the dye being released by the 3000th stimulus (Fig. $2 \mathrm{~A}$ ). However, with $100 \mathrm{~Hz}$, much less dye was lost with only $\sim 20 \%$ of the dye being lost by the 3000th stimulus (i.e., during the first minute of stimulation). One possible explanation for this observation is that fewer vesicles may have undergone exocytosis during the high-frequency stimulation because of depression, and it was thus necessary to correct for this. However, with repetitive trains of high-frequency stimulation, a greater proportion of vesicles are released asynchronously both during the stimulus and during the resting period, and substantial asynchronous release usually continued for some time after each train as well (Fig. $2 B$, top trace, arrowhead) (David and Barrett, 2003). We therefore could not simply correct for depression by cumulatively summing quantal contents based on endplate potential (EPP) amplitudes.

To take into account both depression and asynchronous release and thus arrive at the best estimate of the total number of vesicles exocytosed during the stimulation at $10 \mathrm{~Hz}$ versus 100 $\mathrm{Hz}$, electrical recordings were made from endplates stimulated with the same protocols used to unload FM1-43 dye (Fig. 2 B). To estimate the total number of quanta/vesicles that had undergone exocytosis at each stimulus frequency by the 3000th stimulus, a time point at which a significant difference in the amount of dye lost at the two frequencies was apparent, we measured the area under the voltage trace that was above the baseline resting potential for each train (in millivolts $\cdot$ millisecond), including the enhanced asynchronous release at the ends of the high-frequency trains and divided this by the mean area (in millivolts $\cdot$ millisecond) of the individual miniature endplate potentials (mepps) recorded before the stimulation. This provided us with an estimate of the total number of quanta contributing to the electrical response that had been released at different points during the 10 and 100 $\mathrm{Hz}$ stimulation. However, at $100 \mathrm{~Hz}$, there was also some increase in baseline. This was partly attributable to EPPs occurring before the previous one had decayed to baseline as well as asynchronous release. Since it was difficult to distinguish how much the increase in baseline was attributable to the summation of voltage from successive EPPs versus asynchronous release, we corrected the area under the curve during the stimulation by the amount of the increased baseline, which reduced by $\sim 30 \%$ the original calculation of the summed quantal content. However, this is clearly an overcorrection as much of the increase in baseline, especially toward the end of train was attributable to asynchronous release. The corrected calculated quanta were summed and plotted against stimulus number at every 100th stimulus (Fig. 2C). The data show that, by the 3000th stimulus, fewer vesicles had been released with the $100 \mathrm{~Hz}$ stimulation; however, until the $100-$ 200th stimulus, the number of quanta/vesicles that were released 
did not differ appreciably between the 10 and $100 \mathrm{~Hz}$ stimulation. To determine whether the lesser amount of dye loss observed with $100 \mathrm{~Hz}$ stimulation (Fig. 2A) could be accounted for by fewer vesicles undergoing exocytosis, we performed a FM1-43 destaining experiment with greater temporal resolution for the first 500 stimuli. Figure $2 D$ shows that during the first $100-$ 200 stimuli, dye loss was greater with $10 \mathrm{~Hz}$ compared with $100 \mathrm{~Hz}$ stimulation, similar to the data shown in Figure $2 A$. We then plotted the average normalized FM intensity at different time points against the summed quantal content at each point (Fig. 2E). With the $10 \mathrm{~Hz}$ stimulation, the summed quantal content and FM dye loss had a linear relationship. However, with $100 \mathrm{~Hz}$ stimulation, the relationship indicated that there was less dye loss than would be expected from the amount of transmitter released. In fact, virtually no dye loss was observed even after 10,000 quanta/vesicles had undergone exocytosis.

FM2-10 dye unloading is similar to that of FM1-43 both with 10 and 100 $\mathrm{Hz}$ stimulation

What might account for the different rates of dye loss at the different stimulation frequencies? Several possibilities were considered. First, the actual mechanism of vesicle fusion might differ during $10 \mathrm{~Hz}$ versus 100 $\mathrm{Hz}$ stimulation, resulting in different amounts of dye loss, even though the same amount of transmitter was being released. Second, different pools of vesicles might undergo exocytosis with the different frequencies of stimulation. For example, the $100 \mathrm{~Hz}$ stimulus might mobilize vesicles from a pool that was not loaded by the standard 10 Hz loading protocol, and exocytosis of these vesicles would maintain transmission but not result in dye loss. Third, a greater proportion of vesicles that had already released their dye might be rapidly recycled, filled with transmitter, and exocytosed again during the $100 \mathrm{~Hz}$ stimulation. Such vesicles could maintain transmission but would not contribute to dye loss.

Several modes of vesicle fusion and recycling have been described (Rizzoli and Betz, 2005; Harata et al., 2006b; He and Wu, 2007; Rizzoli and Jahn, 2007; Zhu et al., 2009) as indicated in Figure 3A. In one, the vesicle fully collapses into the terminal membrane after fusion, releasing all of its contents, including transmitter and FM dye. This has been referred to as classical full collapse fusion. In the second, termed "kiss-and-run" or "transient fusion," a small transient fusion pore connects the vesicle interior to the outside solution, resulting in the release of transmitter, but the pore closes before all of the FM dye can departition from the lipid of the vesicle membrane. The importance of these two modes of exocytosis varies depending on the species, the type of syn-
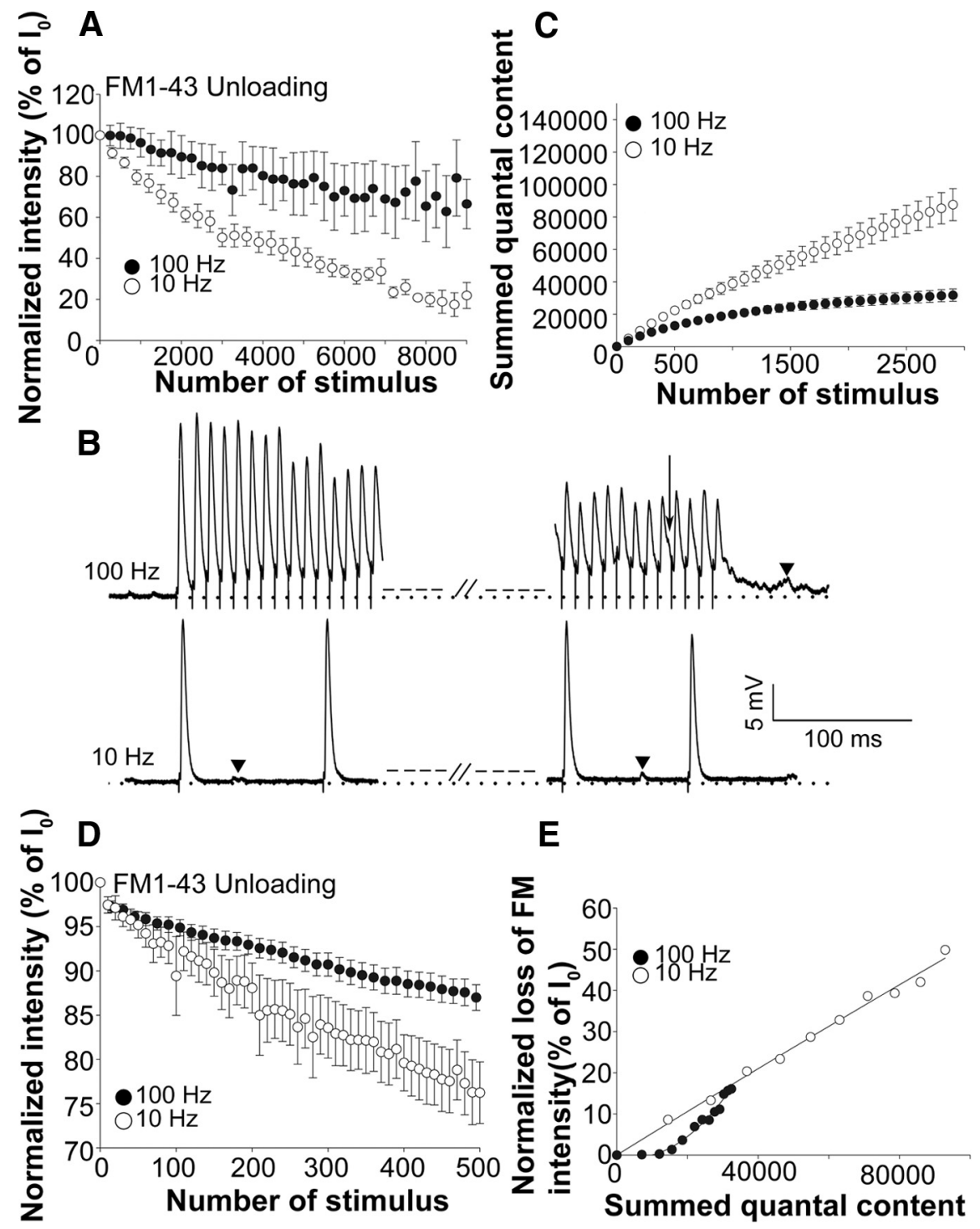

Figure 2. FM1-43 destaining with 10 and $100 \mathrm{~Hz}$ stimulation. $A, \mathrm{FM} 1-43$ destaining at $10 \mathrm{~Hz}$ (white circles; $n_{\text {end }}=7 ; N_{\exp }=7$ ) and $100 \mathrm{~Hz}$ (black circles; $n_{\text {end }}=6 ; N_{\text {exp }}=6$ ). In both cases, loading was with $10 \mathrm{~Hz}$ stimulation for 30 min with 5 min poststimulus dye incubation. Destaining was performed with $1 \mathrm{~s}$ trains separated by $1 \mathrm{~s}$ rest periods the same as the loading protocol. $\boldsymbol{B}$, EPP traces with 10 or $100 \mathrm{~Hz}$ stimulation showing the beginning and the end of the first train (for both the 10 and $100 \mathrm{~Hz}$ stimulation, the endplates received a total of 3000 stimuli). In the top trace, the arrow indicates asynchronous release during an EPP, and the arrowhead indicates extensive asynchronous release at the end of the train. The arrowheads in the bottom trace indicate mepps, but these were included in our measurements of asynchronous release if they occurred during the train. $\boldsymbol{C}$, A graph of summed quantal content plotted against the number of stimuli and calculated as described in the text. White circles, $10 \mathrm{~Hz}\left(n_{\text {end }}=4 ; N_{\text {exp }}\right.$ $=4)$; black circles, $100 \mathrm{~Hz}\left(n_{\text {end }}=5 ; N_{\exp }=5\right.$ ). Depression was noticeable after 200 stimuli with $100 \mathrm{~Hz}$ stimulation. $D$, FM1-43 destaining at $10 \mathrm{~Hz}$ (white circles; $n_{\text {end }}=5 ; N_{\text {exp }}=5$ ) and $100 \mathrm{~Hz}$ (black circles; $n_{\text {end }}=12 ; N_{\text {exp }}=12$ ) during the first 500 stimuli. $\boldsymbol{E}$, A graph of normalized loss of FM dye intensity plotted against the summed quantal content, calculated from the average values from $\boldsymbol{A}$ and $\boldsymbol{C}$. White circles, $10 \mathrm{~Hz}$; black circles, $100 \mathrm{~Hz}$. The lines are regression curves calculated from the data and fitted to either a linear $(10 \mathrm{~Hz})$ or a polynomial $(100 \mathrm{~Hz})$ curve using SigmaPlot software.

apse, and the stimulus conditions (Neher and Marty, 1982; Klingauf et al., 1998; Alés et al., 1999; Stevens and Williams, 2000; Klyachko and Jackson, 2002; Wang et al., 2003; Fulop et al., 2005) and both can coexist in a given nerve terminal (Koenig and Ikeda, 1996; Richards et al., 2000, 2003; Gandhi and Stevens, 2003) (Fig. 3A).

Since there is considerable evidence to support full collapse exocytosis at many synapses, at least under the stimulation protocols we used, we made the initial assumption in our studies, that full collapse exocytosis was used at both the 10 and $100 \mathrm{~Hz}$ stimulation frequencies. Several possibilities then exist for why 

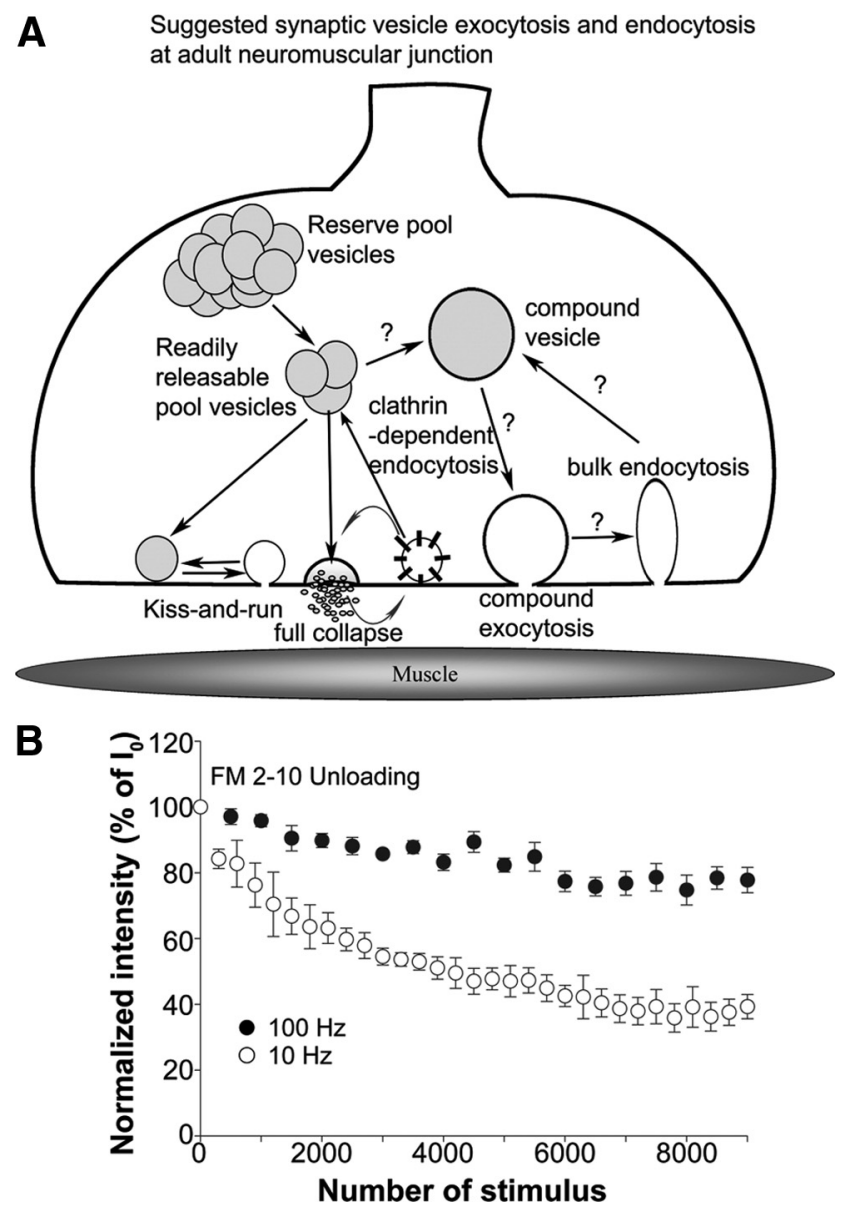

Figure 3. Synaptic vesicle exocytosis and endocytosis at the NMJ. $A$, Schematic model of possible modes of vesicle exocytosis and endocytosis at the adult mouse neuromuscular junction. Note that the existence of compound vesicles and release by compound exocytosis has not yet been demonstrated at the NMJ. B, FM2-10 destaining at $10 \mathrm{~Hz}$ (white circles; $n_{\text {end }}=5 ; N_{\text {exp }}=5$ ) and $100 \mathrm{~Hz}$ (black circles; $n_{\text {end }}=5 ; N_{\exp }=5$ ).

FM1-43 dye destaining was much less at $100 \mathrm{~Hz}$ than was expected from the number of vesicles undergoing fusion. First, there might be insufficient time for the dye to departition from the cell surface membrane after full collapse exocytosis because of the high rate of vesicle membrane addition with $100 \mathrm{~Hz}$ stimulation. To determine whether slow diffusion of FM1-43 from the membrane could explain the smaller amount of dye loss, we performed similar experiments using FM2-10, which diffuses four times faster than FM1-43. The measured dissociation times have been reported as $2.7 \mathrm{~s}$ for FM1-43 and $0.7 \mathrm{~s}$ for FM2-10 (Ryan et al., 1996). As shown in Figure 3B, the amount of dye loss for FM2-10 was also less at $100 \mathrm{~Hz}$ compared with at $10 \mathrm{~Hz}$, not differing appreciably for the dye loss of FM1-43 (Fig. 2A). We also performed a similar high-frequency stimulation protocol, but increased the intervening periods of rest 10 times, thus allowing more time for FM1-43 to diffuse from the surface membrane before making the fluorescence measurements. However, this also did not alter the dye loss with $100 \mathrm{~Hz}$ stimulation (data not shown). These observations suggest that the less amount of dye lost at $100 \mathrm{~Hz}$ stimulation was not attributable to the slow diffusion of FM1-43 from the cell surface membrane but rather that different mechanisms of exocytosis or reuse were used at the two frequencies.
Characteristics of endocytosis at adult mouse neuromuscular junctions with $100 \mathrm{~Hz}$ stimulation

We next addressed the possibility that a different pool of vesicles, which was not loaded with $10 \mathrm{~Hz}$ stimulation, underwent exocytosis during the $100 \mathrm{~Hz}$ stimulation, thus contributing to the slow dye loss seen at this frequency. To load such vesicle pools with FM1-43, we used a $100 \mathrm{~Hz}$ stimulus with 5 min poststimulus uptake (Fig. $1 A$ ), since such intense stimulation has been shown to mobilize vesicles that do not undergo exocytosis with less intense, lower frequency stimulation (Rizzoli and Betz, 2005). First, we examined the vesicles loaded with $100 \mathrm{~Hz}$ stimulation to see whether they behaved similarly to those loaded with $10 \mathrm{~Hz}$. In contrast to $10 \mathrm{~Hz}$ stimulation (Fig. $1 \mathrm{~B}$ ), with the $100 \mathrm{~Hz}$ stimulation, dye uptake occurred more linearly during the stimulation period, with a greater variability among the endplates, especially at early stages of stimulation (Fig. $4 A$ ). This suggests that the degree of dye uptake varied more between endplates at $100 \mathrm{~Hz}$ compared with $10 \mathrm{~Hz}$ stimulation early in the stimulation period. Also, there was considerable dye uptake after cessation of the 100 $\mathrm{Hz}$ stimulus (Fig. 4 B). Such uptake likely corresponds to a bulk form of endocytosis described by others (Heuser and Reese, 1973; Miller and Heuser, 1984; Koenig and Ikeda, 1996; Richards et al., 2003; Jockusch et al., 2005; Rizzoli and Betz, 2005) (Fig. 3A). The mean pixel intensity values after wash were $5151 \pm 343\left(n_{\text {end }}=\right.$ $\left.91 ; N_{\exp }=3\right)$ versus $17,016 \pm 1595\left(n_{\text {end }}=68 ; N_{\exp }=7\right)$ for dye uptake without and with $5 \mathrm{~min}$ poststimulus dye application, respectively (Fig. $4 B$ ), and these were the statistically significant $(p<0.01)$. With $100 \mathrm{~Hz}$ stimulation, the mean pixel intensity increased by $11,865 \pm 1938$ (70\% of the total dye uptake) after cessation of the stimulus. This increase was four times greater than the value with the $10 \mathrm{~Hz}$ stimulus (Figs. $4 \mathrm{~B}, 1 \mathrm{C}$ ). Even when the duration of the stimulus was reduced to $1 \mathrm{~min}$, rather than 3 min, substantial dye uptake occurred, mostly after cessation of the stimulus (data not shown). These results suggest that some signal produced by $100 \mathrm{~Hz}$ stimulation, but not $10 \mathrm{~Hz}$, triggers this delayed endocytosis. The vesicles labeled during the delayed endocytosis might become part of the reserve pool of vesicles, which has been reported to be labeled by such intense stimulation (Richards et al., 2000, 2003). Another interesting observation was that, during the stimulation period, less dye was taken up at 100 $\mathrm{Hz}$ than at $10 \mathrm{~Hz}$ (Figs. $4 B, 1 C$ ), and the intense uptake only occurred when the stimulus was stopped. This was true for different durations of stimulation (data not shown) suggesting that some signal produced by $100 \mathrm{~Hz}$ stimulation suppresses this form of endocytosis during the stimulus.

Recently, a brefeldin A (BFA)-sensitive, AP-3-mediated form of endocytosis has been detected at mature mouse hippocampal synapses (Scheuber et al., 2006; Voglmaier et al., 2006; Danglot and Galli, 2007; Voglmaier and Edwards, 2007). A form of vesicle cycling and FM1-43 dye uptake that is sensitive to BFA or L-type calcium channel blockers has also been observed in immature mouse and chick motor axons before myotube contact (Zakharenko et al., 1999; Hata et al., 2007) (K. Hata and L. T. Landmesser, unpublished observations). Thus, we further characterized this delayed endocytosis by applying either BFA $(10 \mu \mathrm{g} / \mathrm{ml})$ or nifedipine $(5 \mu \mathrm{M})$. Both BFA and nifedipine reduced the mean pixel intensity of endplates to $12,868 \pm 656\left(n_{\text {end }}=136 ; N_{\exp }=7\right)$ $(p<0.05)$ and $10,009 \pm 739\left(n_{\mathrm{end}}=79 ; N_{\exp }=5\right)(p<0.01)$, respectively (Fig. $4 B$ ). We were also interested to determine whether this delayed endocytosis was coupled to exocytosis. Thus, BoNTXA, which cleaves the vesicle fusion protein SNAP25 , and thus prevents undocked vesicles from docking with the surface plasma membrane before exocytosis, was used. BoNTXA 
significantly reduced the poststimulus dye uptake (mean pixel intensity after wash was reduced to $11,285 \pm 1100)\left(n_{\text {end }}=50\right.$; $\left.N_{\text {exp }}=4\right)(p<0.01)$ (Fig. $\left.4 B\right)$. Together, our results suggest that different modes of endocytosis occur at 10 and $100 \mathrm{~Hz}$ stimulation both during and after stimulation.

The difference in dye loss with $10 \mathrm{~Hz}$ versus $100 \mathrm{~Hz}$ stimulation persists even though a different pool of vesicles was loaded with the $100 \mathrm{~Hz}$ stimulation We then determined how this pool of vesicles loaded with $100 \mathrm{~Hz}$ stimulation was mobilized by either 10 or $100 \mathrm{~Hz}$ stimulation. With either 10 or $100 \mathrm{~Hz}$ trains, little dye was lost even after 4000 stimuli (Fig. $4 C$ ). This indicates that the vesicles loaded with $100 \mathrm{~Hz}$ stimulation belong to a different pool than those loaded with $10 \mathrm{~Hz}$ and that they are not immediately available for subsequent release. However, after 4000 stimuli, the $10 \mathrm{~Hz}$ stimulation began to result in dye loss, whereas little dye was lost with the $100 \mathrm{~Hz}$ stimulation, even after 9000 stimuli (Fig. 4C). The large error bars after 4000 stimuli at $10 \mathrm{~Hz}$ were the result of different endplates starting to unload at different time points.

We next provided a $2 \mathrm{~h}$ rest period after the $100 \mathrm{~Hz}$ loading, as other studies have shown that the pool of vesicles loaded with such intense stimulation, probably as a result of bulk endocytosis, requires additional time to become competent to undergo exocytosis with stimulation (Richards et al., 2000; Clayton et al., 2009). As shown in Figure $4 D$, after such a rest period, the labeled vesicles were now able to be released, but once again the amount of destaining at $100 \mathrm{~Hz}$ was considerably less than that at $10 \mathrm{~Hz}$. In this same series of experiments, the stimulus frequency was switched from 10 to $100 \mathrm{~Hz}$ (Fig. $4 D$, white and black triangles, respectively) or 100 to $10 \mathrm{~Hz}$ (Fig. $4 \mathrm{D}$, black and white circles, respectively) at the 9000th stimulus. In both cases, this resulted in an immediate switch in the destaining behavior (Fig. 4D). These results indicate that, even though a different pool had presumably been loaded by the $100 \mathrm{~Hz}$ compared with $10 \mathrm{~Hz}$ loading protocol, different amounts of dye were lost when these vesicles were unloaded with $10 \mathrm{~Hz}$ versus $100 \mathrm{~Hz}$ stimulation.

\section{Rapid reuse of vesicles is triggered by $100 \mathrm{~Hz}$ stimulation}

We next attempted to assess whether rapid reuse of vesicles was responsible for the much smaller amount of dye loss with $100 \mathrm{~Hz}$ stimulation by applying folimycin (Ertunc et al., 2007). Folimycin disrupts the proton gradient across the vesicle membrane and thus prevents the refilling with transmitter of previously used vesicles. When such vesicles undergo exocytosis, they do not release any transmitter, which results in a decline in EPP amplitude. During a single $1 \mathrm{~s}$ train at $10 \mathrm{~Hz}$ and at the normal level of $\mathrm{Ca}^{2+}$ stimulus.
B

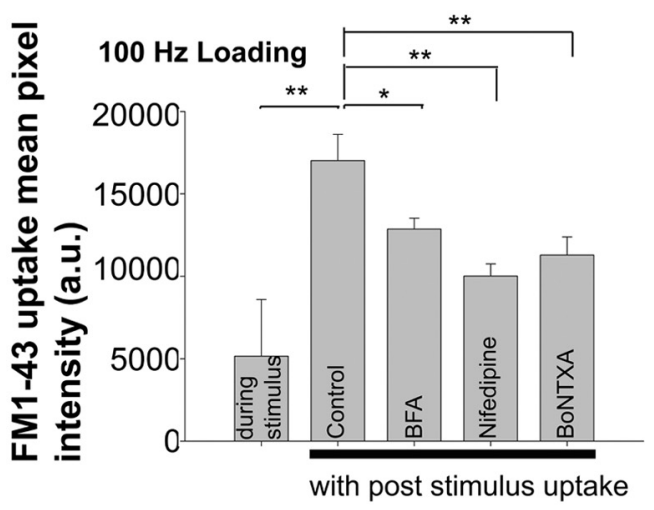

D

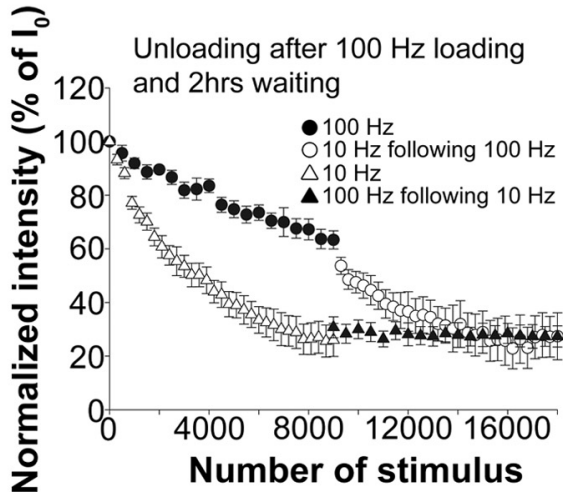

Figure 4. The FM1-43 destaining with 10 or $100 \mathrm{~Hz}$ stimulation after loading at $100 \mathrm{~Hz}$. A, FM1-43 uptake with a $100 \mathrm{~Hz}, 3 \mathrm{~min}$

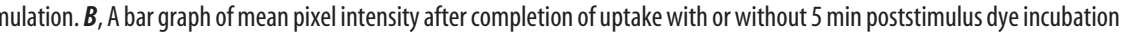
$595\left(n_{\text {end }}=68 ; N_{\exp }=7\right)$ with an additional 5 min poststimulus uptake. BFA reduced the poststimulus uptake intensity to 的 $\left.136 ; N_{\text {exp }}=7\right)$, nifedipine reduced it to $10,009 \pm 739\left(n_{\text {end }}=79 ; N_{\exp }=5\right)$, and BoNTXA reduced it to and after stimulation. C, FM1-43 unloading with 10 or $100 \mathrm{~Hz}$ stimulus after $100 \mathrm{~Hz}$ loading. Black circles, $100 \mathrm{~Hz}$ ( $n=5 ; \mathrm{N}=$ 5). White circles, $10 \mathrm{~Hz}\left(n_{\text {end }}=3 ; N_{\text {exp }}=3\right.$ ). $\boldsymbol{D}$, After $100 \mathrm{~Hz}$ loading, muscles were allowed to rest $2 \mathrm{~h}$ in low-Ca ${ }^{2+}$ Tyrode's solution after which they were subjected to either 10 or $100 \mathrm{~Hz}$ stimulation. After this rest period, vesicles that were loaded with $100 \mathrm{~Hz}$ stimulation became available for destaining, but considerably less dye was lost at $100 \mathrm{~Hz}$ compared with $10 \mathrm{~Hz}$. Black circles

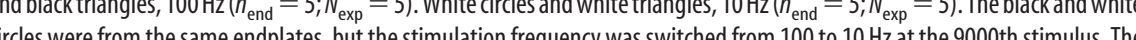
white and black triangles were from the same endings, but the stimulation frequency was switched from 10 to $100 \mathrm{~Hz}$ at the 9000 th

(2 mM), the EPP amplitude was not altered by folimycin (Fig. $5 A$ ). During a single $100 \mathrm{~Hz}$ train, EPP amplitudes declined to $\sim 60 \%$ of the starting value because of depression; however, this decline was not significantly increased by folimycin (Fig. $5 B$ ). These observations suggest that either there is no rapid reuse of vesicles during such short stimulations or that the proportion of vesicles reused is sufficiently small compared with those that are mobilized de novo so as to be undetectable. At vertebrate NMJs, the estimated total number of vesicles is $\sim 250,000$ (Elmqvist and Quastel, 1965; Schofield and Marshall, 1980; Reid et al., 1999), which is considerably larger than the vesicle number at many central synapses, which may be on the order of several hundred. Thus, the contribution of this large vesicle pool might contribute more to maintaining effective neuromuscular transmission with high-frequency stimulation than the rapid reuse of vesicles. In fact, many studies have shown that the reserve pool is recruited more effectively with intense stimulation at NMJs (Rizzoli and 

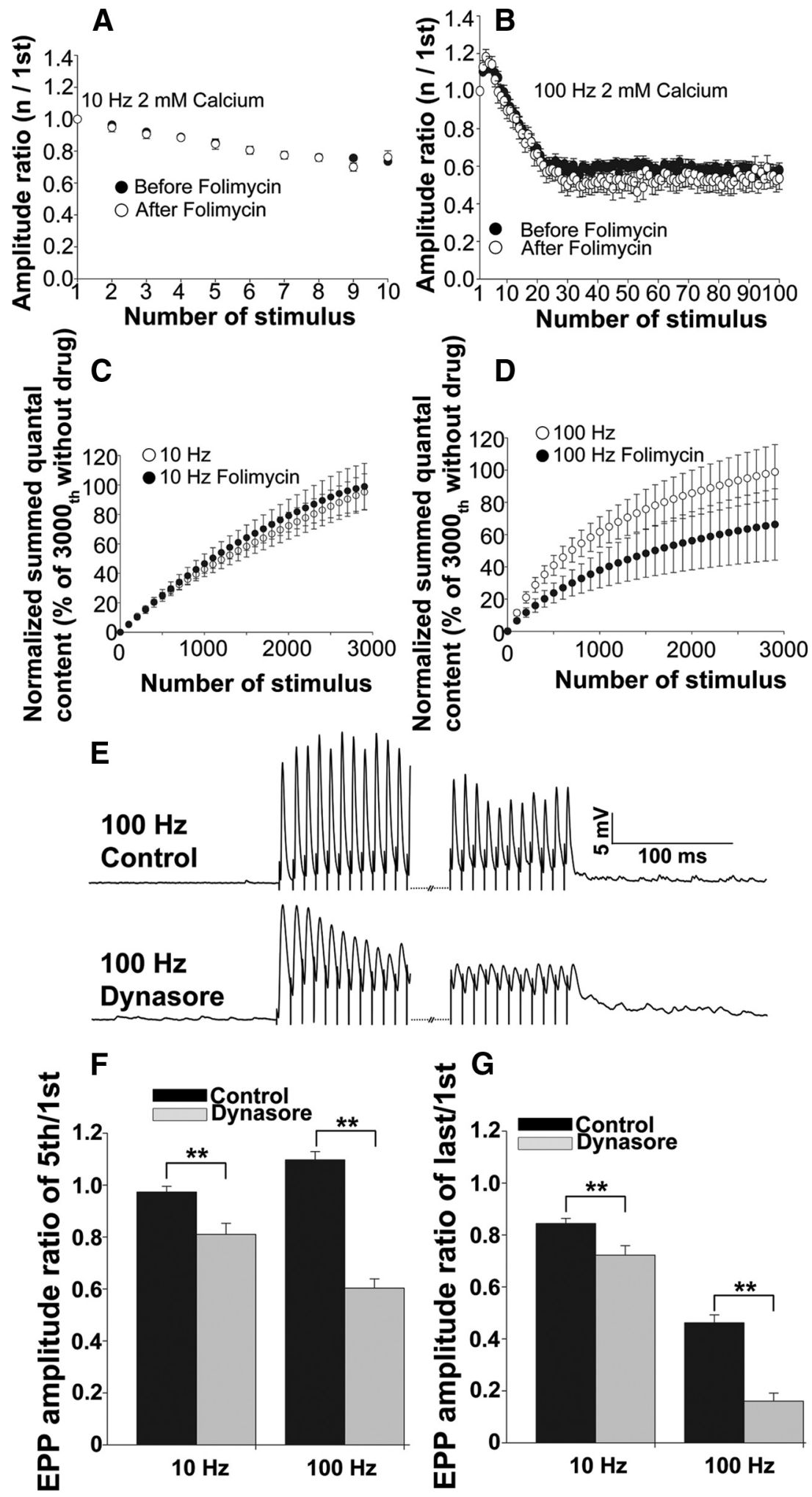

Figure 5. The effect of folimycin and dynasore on EPP amplitude with 10 or $100 \mathrm{~Hz}$ stimulation. $\boldsymbol{A}$, The ratio of the amplitude of the $n$ th/first EPP with a $10 \mathrm{~Hz}$ single train in the presence of (white circles; $n_{\text {end }}=4 ; N_{\exp }=4$ ) or absence of (black circles; $n_{\text {end }}=$ $14 ; N_{\exp }=14$ ) folimycin. $\boldsymbol{B}$, Similar EPP amplitude ratio with a $100 \mathrm{~Hz}$ single train with (white circles; $n_{\operatorname{end}}=8 ; N_{\exp }=8$ ) or without (black circles; $n_{\text {end }}=19 ; N_{\exp }=19$ ) folimycin. C, Normalized summed quantal content for $10 \mathrm{~Hz}$ stimulation without folimycin (white circles; $n_{\text {end }}=4 ; N_{\text {exp }}=4$ ) and with folimycin (black circles; $n_{\text {end }}=5 ; N_{\text {exp }}=5$ ). The summed quantal content values were normalized to the value of the 3000 th stimulus without folimycin. $D$, Normalized summed quantal content for $100 \mathrm{~Hz}$ without folimycin (white triangles; $n_{\text {end }}=5 ; N_{\text {exp }}=5$ ) and with folimycin (black triangles; $n_{\text {end }}=5 ; N_{\text {exp }}=5$ ). The summed quantal content values were normalized to the value of the 3000th stimulus without folimycin. The data for $10 \mathrm{~Hz}$ without folimycin and $100 \mathrm{~Hz}$ without folimycin in $\boldsymbol{C}$ and $\boldsymbol{D}$ are the same data set as shown in Figure 2 C but normalized to the value at the 3000th stimulus. $\boldsymbol{E}$, An example of a train of EPPs with $100 \mathrm{~Hz}$ stimulation recorded from a control NMJ (top) and a different
Betz, 2005). To determine whether sustained periods of stimulation resulted in an increase in vesicle reuse or not, we stimulated with $1 \mathrm{~s}$ trains interspersed with $1 \mathrm{~s}$ rest periods for $10 \mathrm{~min}$ at $10 \mathrm{~Hz}$ (3000 stimuli) or $1 \mathrm{~min}$ at $100 \mathrm{~Hz}(3000$ stimuli) in the presence or absence of folimycin and measured the area under the EPPs as well as any asynchronous release during either the stimulation or resting periods and calculated the quantal content as described earlier. We also corrected for the overestimation of summed quantal content caused by the superimposition of EPPs at $100 \mathrm{~Hz}$ as described previously. Since folimycin did not affect the increase in baseline because of the superimposition of EPPs, we reduced the value at $100 \mathrm{~Hz}$ by $30 \%$ as we had done for the data presented in Figure 2C. This corrected summed quantal content value was normalized with the value obtained without folimycin at the 3000th stimuli for both 10 and $100 \mathrm{~Hz}$ and plotted as shown in Figure 5, $C$ and $D$. Whereas there was little effect of folimycin at $10 \mathrm{~Hz}$ (Fig. 5C), at $100 \mathrm{~Hz}$, there was a $\sim 40 \%$ decline in the summed quantal content in the presence of folimycin (Fig. 5D). The summed quantal content values at the 3000th stimulus with $100 \mathrm{~Hz}$ stimulation, were $33,219 \pm 5734$ and $22,324 \pm 7457$ without and with folimycin, respectively, and were significantly different $(p<0.01)$. Even as early as the 200th stimulus, the decline in summed quantal content caused by folimycin was obvious $(6993 \pm 1159$ and $3889 \pm 967$ without and with folimycin, respectively; $p<0.01)$. These results suggest that stimulation at $100 \mathrm{~Hz}$ but not 10 $\mathrm{Hz}$ triggers a rapid reuse of vesicles that had undergone either a kiss-and-run or a very rapid full collapse followed by a rapid endocytosis. Similar rapid recycling has been observed in hippocampal synapses (Harata et al., 2006a).

Next, we investigated the role of dynamin in transmission at 10 and $100 \mathrm{~Hz}$ by applying the dynamin I and II GTPase inhibitor, dynasore. Dynamin acts on the process of synaptic vesicle scission from the plasma membrane, which requires

dynasore-treated NMJ (bottom). The first 10 responses and the last 10 responses are shown. Dynasore treatment inhibited facilitation and greatly enhanced depression. $\boldsymbol{F}$, The ratio of the amplitude of the fifth/first EPP with either a 10 or $100 \mathrm{~Hz}$ single train in the presence of (gray; $n_{\text {end }}=7 ; N_{\text {exp }}=2$ ) or absence of (black; $n_{\text {end }}=10 ; N_{\exp }=2$ ) dynasore. G, Similar EPP amplitude ratio of last/first EPP with either a 10 or $100 \mathrm{~Hz}$ single train with (gray; $n_{\text {end }}=7 ; N_{\text {exp }}=2$ ) or without (black; $\left.n_{\text {end }}=10 ; N_{\text {exp }}=2\right)$ dynasore. 
GTP hydrolysis, and thus is an important regulator of endocytosis (Xu et al., 2008; Lu et al., 2009; Tsai et al., 2009; Chung et al., 2010). Interestingly, dynasore strongly enhanced depression at $100 \mathrm{~Hz}$ stimulation compared with control, even during the initial stimulus trains. However, it had little effect on EPP amplitude during 10 $\mathrm{Hz}$ stimulation (Fig. $5 E-G$ ). These data suggest that, at $100 \mathrm{~Hz}$, but not at $10 \mathrm{~Hz}$, dynamin-dependent endocytosis was required to maintain effective transmission. However, even after prolonged stimulation, sufficient to deplete the pool of releasable vesicles, at both 10 and $100 \mathrm{~Hz}$, transmission was not completely abolished by dynasore, and at $10 \mathrm{~Hz}$, gradual recovery was seen (data not shown). These data suggest that there may be a dynamin-independent form of endocytosis in mouse NMJs. We cannot at present exclude that another isoform of dynamin that is not inhibited by dynasore, which inhibits dynamin 1 and 2, mediates endocytosis. Alternatively, the sites on dynamin that are blocked by dynasore may not always be accessible in the intact presynaptic terminal, and these might be more accessible during the form of endocytosis that is triggered by $100 \mathrm{~Hz}$ stimulation. The existence of both dynamin-dependent and -independent endocytosis has been reported in the calyx of Held (Xu et al., 2008), in superior cervical ganglion neurons (Lu et al., 2009), in bovine chromaffin cells (Tsai et al., 2009), and the pool of vesicles responsible for spontaneous transmitter release was recently reported to be dynamin independent in hippocampal GABAergic synapses (Chung et al., 2010). A more detailed investigation of the roles of dynamin at 10 and $100 \mathrm{~Hz}$ stimulation is currently under study. However, together, our data indicate that $100 \mathrm{~Hz}$ stimulation triggers the rapid reuse of vesicles and that transmission at $100 \mathrm{~Hz}$ is much more sensitive to dynamin inhibition than that at $10 \mathrm{~Hz}$, even for the same number of stimuli.

\section{A MLCK-myosin II pathway is required for the mode of synaptic vesicle cycling that loses less dye and that is used during $100 \mathrm{~Hz}$ stimulation}

A MLCK signaling pathway (Fig. 6A), shown to be required to maintain effective transmission at high stimulation frequencies, was initially discovered through studies of neural cell adhesion molecule (NCAM)-deficient mouse NMJs, which were unable to maintain effective transmission at high stimulus repetition rates and also exhibited cyclical periods of total transmission failures when stimulated at $100 \mathrm{~Hz}$ and above (Polo-Parada et al., 2001). Subsequent experiments demonstrated that such total transmission failures at $100 \mathrm{~Hz}$ stimulation could be produced in wildtype NMJs by blocking MLCK with either ML-9 (Polo-Parada et al., 2004) or by the introduction of a peptide inhibitor of MLCK
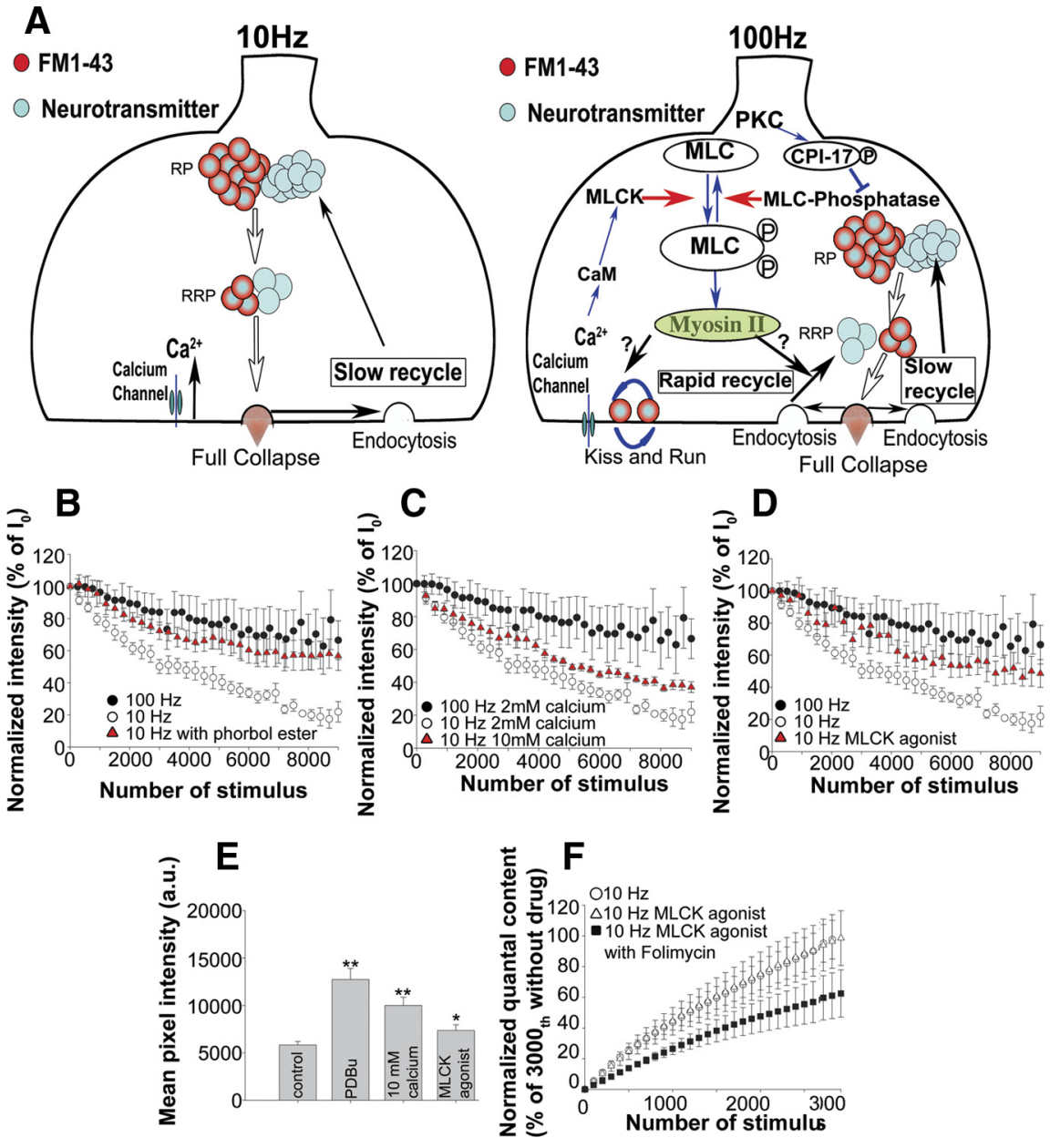

Figure 6. The MLCK pathway may act to trigger a switch in the mode of dye destaining used during $10 \mathrm{~Hz}$ versus $100 \mathrm{~Hz}$ stimulation. $A$, Schematic model of suggested cellular and molecular mechanisms for dye loss at 10 and $100 \mathrm{~Hz}$. A MLCK and myosin -regulated pathway is needed to maintain synaptic transmission at high-frequency stimulation but not at low-frequency stim$B, F M 1-43$ destaining at $10 \mathrm{~Hz}$ in the presence of a phorbol ester (red triangles; $n_{\text {end }}=9 ; N_{\text {exp }}=9$ ) compared with the 作 $10 \mathrm{~Hz}$. The $100 \mathrm{~Hz}$ a and $10 \mathrm{exp}=5$ compared with controldestaining at 100 or of FM1-43 mean pixel intensity remaining in endplates after completion of $30 \mathrm{~min}$ of a $10 \mathrm{~Hz}$ destaining in the presence of the

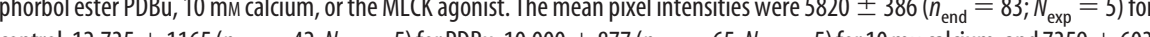
$\left(n_{\text {end }}=75 ; N_{\text {exp }}=5\right)$ for the MLCK agonist peptide. $\boldsymbol{F}$, Normalized summed quantal content measured as in Figure $5, C$ and $D$. White circles, $10 \mathrm{~Hz}$ without folimycin ( $n=4$; same as Fig. 5 ( for comparison); white triangles, $10 \mathrm{~Hz}$ with the MLCK agonist peptide $\left(n_{\text {end }}=4 ; N_{\text {exp }}=4\right)$; black squares, $10 \mathrm{~Hz}$ with the MLCK agonist and folimycin $\left(n_{\text {end }}=5 ; N_{\exp }=5\right)$.

into the presynaptic terminal (Polo-Parada at al., 2005). Blocking downstream targets of MLCK, for example MLC (the regulatory light chain of myosin), with an inhibitor peptide or blocking myosin II with the myosin II ATPase-specific inhibitor, blebbistatin (Polo-Parada et al., 2004, 2005), also caused transmission failures with high-, but not low-frequency stimulation, further supporting the importance of the MLCK-myosin II pathway in maintaining synaptic transmission with high, but physiological (Gorassini et al., 2000), stimulus frequencies.

The fact that the requirement for the MLCK pathway to prevent transmission failures was frequency dependent (PoloParada et al., 2005), together with the different modes of vesicle cycling we observed with 10 or $100 \mathrm{~Hz}$ stimulation, led us to hypothesize that the MLCK pathway might be needed to engage the mode of vesicle recycling used at high frequency that loses less 
dye. A previous study (Polo-Parada et al., 2004) also provided evidence that PKC activates the MLC-myosin II pathway possibly by inhibition of MLC-P (myosin light chain phosphatase). To see whether activation of PKC could engage the MLCK pathway, even during $10 \mathrm{~Hz}$ stimulation, and thus alter the mode of cycling, either of the phorbol esters, PMA or phorbol 12,13dibutyrate $(\mathrm{PDBu})$, was applied to activate $\mathrm{PKC}$ during dye destaining at $10 \mathrm{~Hz}$ stimulation. Normally, $10 \mathrm{~Hz}$ destaining caused rapid dye loss (Fig. $2 \mathrm{~A}$ ), and by the end of the stimulation, the total mean pixel intensity was reduced to approximately onehalf $\left(5820 \pm 386 ; n_{\text {end }}=83 ; N_{\exp }=5\right)$ of the fully loaded value (Fig. 1C). However, phorbol ester treatment resulted in less dye loss, usually seen only with $100 \mathrm{~Hz}$ stimulation. Significantly $(p<0.01)$ more dye remained (mean pixel intensity, 12,735 \pm $1165 ; n_{\text {end }}=42 ; N_{\exp }=5$ ) after the 9000th stimulus (Fig. $6 B, E$ ). These observations suggest that, even with $10 \mathrm{~Hz}$ stimulation, $\mathrm{PKC}$ activation is able to change the vesicle release mode to a mode in which less dye is lost. In summary, activation of the MLCK pathway alone, is sufficient to prevent transmission failures at $100 \mathrm{~Hz}$ and also to trigger a mode of vesicle cycling in which less dye is lost.

Next, since the MLCK pathway is regulated by $\mathrm{Ca}^{2+}$ (Fig. 6A), we speculated that an upstream signal that initiates the activation of this pathway might be an increase in calcium concentration within the presynaptic terminal. To test the idea, we increased the calcium concentration in the bath from 2 to $10 \mathrm{~mm}$ and examined the FM dye destaining with $10 \mathrm{~Hz}$ stimulation (Fig. 6C,E). This resulted in much less dye being released than during the $10 \mathrm{~Hz}$ destaining in $2 \mathrm{~mm} \mathrm{Ca}^{2+}$, with significantly $(p<0.01)$ more dye remaining after the 9000th stimulus (mean pixel intensity, $10,000 \pm 877 ; n_{\text {end }}=65 ; N_{\exp }=5$ ) (Fig. 6E). These data suggest that a higher calcium concentration within the presynaptic terminal was able to prevent the fast dye loss mode of vesicle exocytosis even with $10 \mathrm{~Hz}$ stimulation and to shift the behavior of release to one that loses less dye, which is usually only observed with high-frequency stimulation.

Next, we tested the effect of activating MLCK by the MLCK agonist peptide, which was previously shown to rescue the total transmission failures in NCAM 180-deficient NMJs when stimulated at high frequency (Polo-Parada et al., 2005). This peptide was also shown to cause phosphorylation of MLC in PC12 cells in the absence of any stimulation, confirming that it caused MLCK to be activated constitutively (Polo-Parada et al., 2005). Introducing the MLCK agonist peptide with the peptide carrier Chariot resulted in less dye loss even at $10 \mathrm{~Hz}$ stimulation (Fig. 6D) and considerably more dye remained after 9000 stimuli (mean pixel intensity, $7359 \pm 603 ; n_{\text {end }}=75 ; N_{\exp }=5$ ) (Fig. $6 E$ ), which differed significantly from the normal $10 \mathrm{~Hz}$ destaining $(p<$ $0.05)$. Our electrophysiological recordings indicated that quantal content was similar when NMJs were treated with the MLCK agonist $(42.53 \pm 5.68$ and $42.16 \pm 5.19$, with or without the MLCK agonist, respectively), suggesting again that transmitter release was normal but FM1-43 dye release was less, similar to that occurring normally with $100 \mathrm{~Hz}$ stimulation.

We then tested whether the greater retention of dye that occurred with MLCK activation at $10 \mathrm{~Hz}$ was caused by the rapid reuse of vesicles, which we had observed by using folimycin during $100 \mathrm{~Hz}$ stimulation. Thus, we activated MLCK and then stimulated NMJs at $10 \mathrm{~Hz}$, with or without folimycin, and measured the summed quantal content. Activation of MLCK alone did not change the summed quantal content (Fig. 6F, white circle and triangle); however, MLCK activation together with folimycin strongly reduced the value of the summed quantal content. This
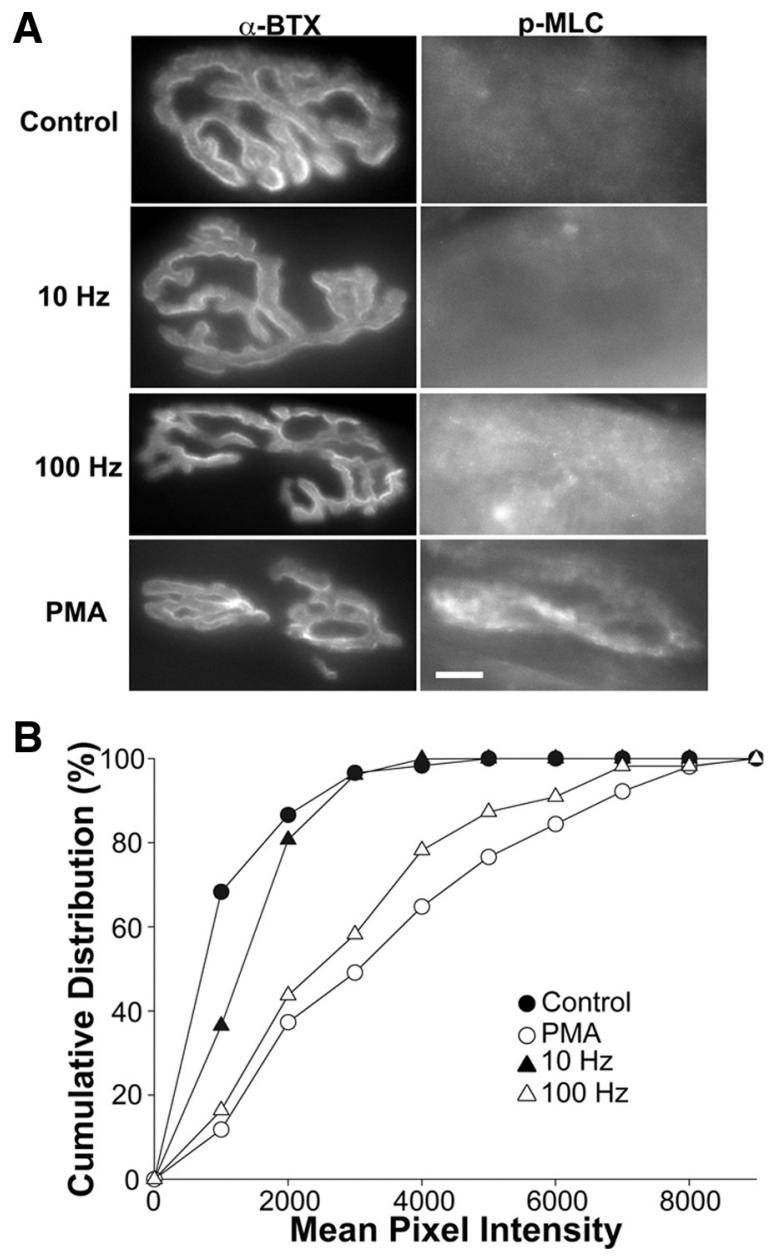

Figure 7. Phospho-MLC is upregulated with PMA treatment or with a $100 \mathrm{~Hz}$ stimulus. $\boldsymbol{A}$, Immunostaining of adult NMJs. Endplates were stained with $\alpha$-bungarotoxin ( $\alpha$-BTX), a postsynaptic marker, and a phosphospecific myosin light chain ( $p-M L C)$ antibody. The $p-M L C$ staining for PMA treated endings and those stimulated at $100 \mathrm{~Hz}$ were upregulated compared with unstimulated controls or those stimulated at $10 \mathrm{~Hz}$. Scale bar, $10 \mu \mathrm{m}$. B, Cumulative distribution of $p-M L C$ staining with various treatments. PMA and $100 \mathrm{~Hz}$ stimulus increased the p-MLC staining greatly. The mean values are as follows: control, $1142 \pm 168\left(n_{\text {end }}=45 ; N_{\exp }=3\right)$; PMA, $3493 \pm 499\left(n_{\text {end }}=49 ; N_{\text {exp }}=4\right) ; 10 \mathrm{~Hz}, 1443 \pm 208\left(n_{\text {end }}=48 ; N_{\exp }=3\right) ; 100 \mathrm{~Hz}$, $2904 \pm 399\left(n_{\text {end }}=53 ; N_{\text {exp }}=4\right)$. The statistical significance determined by the KolmogorovSmirnov test compared with the unstimulated control was $p<0.01$ for $10 \mathrm{~Hz}, p<0.001$ for $100 \mathrm{~Hz}$, and $p<0.001$ for PMA. The values for PMA and $100 \mathrm{~Hz}$ stimulation did not differ significantly, $p=0.765$.

observation demonstrates more directly that activation of the MLCK pathway increases the number of vesicles that are rapidly recycled and reused.

\section{High-frequency stimulation or PMA increases the} phosphorylation of myosin II light chain in intact endplates Activating the MLCK pathway with the MLCK agonist peptide altered the amount of dye loss as well as the mode of vesicle recycling. To see whether changes in the activation of the MLCK pathway actually occurred in intact endplates when their axons were stimulated with 10 or $100 \mathrm{~Hz}$ stimuli or with phorbol ester, immunostaining with an antibody that recognizes MLC when it is phosphorylated on serine 19 and threonine 18 was performed. Phosphorylation by MLCK at these sites on MLC results in activation of myosin II (Somlyo and Somlyo, 2003). Thus, phosphoMLC (p-MLC) staining can be used as an indicator of the state of activation of the MLCK pathway in intact nerve terminals. Im- 
munostaining for $\mathrm{p}$-MLC was performed on frozen sections from semitendinosus muscles that had previously been placed in oxygenated Tyrode's solution and either not treated, treated with PMA, or stimulated at different frequencies. In nonstimulated muscles, p-MLC staining was present (Fig. 7A) as previously reported (Polo-Parada et al., 2005), but as evident from the distribution of endplates with different mean pixel intensities, most had low levels of p-MLC (Fig. 7B). When muscles were treated with 100 nM PMA and rapidly fixed in the presence of phosphatase inhibitors, staining was more intense (Fig. 7A) and the distribution of mean pixel intensities was shifted to higher values (Fig. 7B). This result confirmed that PKC activation led to MLCK activation at NMJs. Next, muscles were either stimulated at 10 or $100 \mathrm{~Hz}$ for several minutes and rapidly fixed toward the end of the stimulation. Stimulation at $10 \mathrm{~Hz}$ increased p-MLC staining only slightly above control levels (Fig. $7 A, B$ ). However, stimulation at $100 \mathrm{~Hz}$ resulted in a clear shift in the distribution of p-MLC levels to higher values (Fig. 7A,B), similar to that caused by PMA. Thus, these observations show that $100 \mathrm{~Hz}$, but not $10 \mathrm{~Hz}$, stimulation strongly activates the MLCK signaling pathway and could serve as the signal to switch to the myosin IIdependent form of vesicle cycling that is engaged at high stimulus frequencies.

\section{$\mathrm{PKC} \varepsilon$ regulates the MLCK pathway}

Among the $\mathrm{PKC}$ isoforms, $\mathrm{PKC} \varepsilon$ is more concentrated in the nervous system (Ono et al., 1988; Koide et al., 1992; Wetsel et al., 1992) and is unique in containing an actin binding domain (Prekeris et al., 1996). It is known to be involved in voltage-gated calcium channel signaling (Maeno-Hikichi et al., 2003), inducing synaptic potentiation at the calyx of Held (Saitoh et al., 2001), regulating glutamate exocytosis from synaptosomes (Prekeris et al., 1996) and the secretion of neuropeptides from Caenorhabditis elegans motor neurons (Sieburth et al., 2007).

To see whether PKC $\varepsilon$ is present in adult NMJs, immunostaining of adult mouse junctions was performed using a $\mathrm{PKC} \varepsilon$-specific antibody. $\mathrm{PKC} \varepsilon$ was localized in a punctate manner at endplates, which were visualized with $\alpha$-bungarotoxin staining for postsynaptic acetylcholine receptors (Fig. $8 A$ ). Staining of cross-sections showed that $\mathrm{PKC} \varepsilon$ was abundant in the presynaptic terminal (Fig. $8 A$ ). To test whether PKC $\varepsilon$ played a role in MLC phosphorylation with 100 $\mathrm{Hz}$ stimulation, NMJs were pretreated with a PKC $\varepsilon$ translocation inhibitor, and then stimulated at either 10 or $100 \mathrm{~Hz}$, fixed, and then immunostained with the p-MLC antibody. With $10 \mathrm{~Hz}$ stimulation, there was no effect of the PKC $\varepsilon$ inhibitor (Fig. $8 B, C$ )
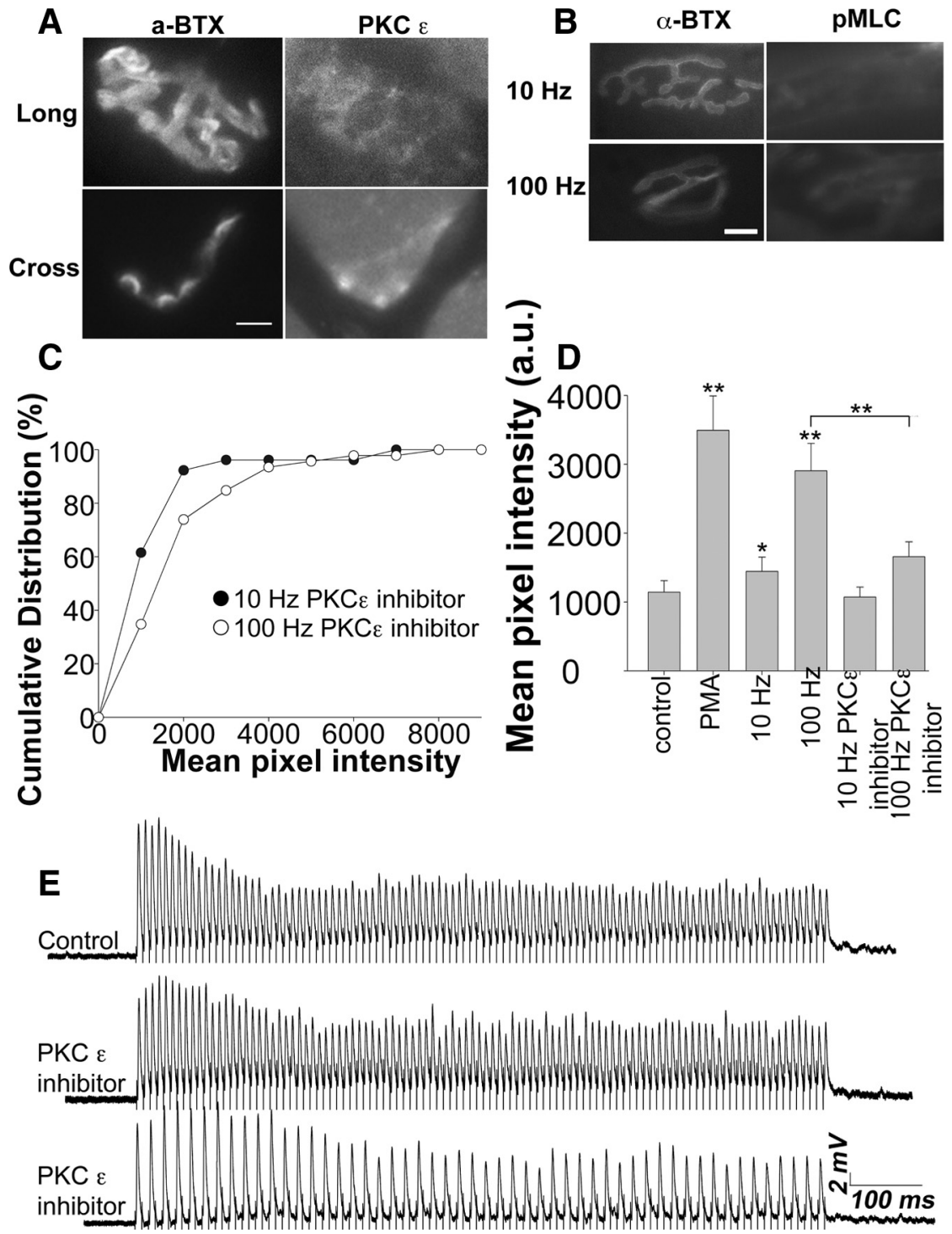

Figure 8. PKC $\varepsilon$ regulates the activation of the MLCK pathway and the effectiveness of synaptic transmission. $\boldsymbol{A}$, Endplates were stained with $\alpha$-BTX (a postsynaptic marker) and with a PKC $\varepsilon$ antibody. The top panel shows an entire endplate from a $50 \mu \mathrm{m}$ longitudinal section viewed from above. The bottom panel is taken from a $12 \mu \mathrm{m}$ transverse section of the muscle and shows the gutters of several endplates visualized with $\alpha$-BTX. The PKC $\varepsilon$ immunostaining is located more peripherally in a presynaptic location. Scale bar, $10 \mu \mathrm{m}$. $\boldsymbol{B}$, Phospho-MLC staining at 10 or $100 \mathrm{~Hz}$ stimulated endings that were pretreated with a PKC $\varepsilon$ translocation inhibitor peptide. Staining was greatly reduced with $100 \mathrm{~Hz}$ stimulation after the PKC $\varepsilon$ inhibitor peptide treatment and was similar to the control value at $10 \mathrm{~Hz}$. Scale bar, $10 \mu \mathrm{m}$. C, Cumulative distribution of p-MLC staining at $10 \mathrm{or} 100 \mathrm{~Hz}$ stimulus pretreated with PKC $\varepsilon$ inhibitor peptide. The mean values are as follows: $10 \mathrm{~Hz}, 1072 \pm 145\left(n_{\text {end }}=52 ; N_{\exp }=3\right) ; 100$ $\mathrm{Hz}, 1657 \pm 216\left(n_{\text {end }}=46 ; N_{\exp }=3\right)$. Statistical significance was determined by Kolmogorov-Smirnov test and was not significant, $p=0.06$. D, A summary bar graph of mean pixel intensities for $p-M L C$ immunostaining of endings under different experimental conditions. PMA treatment and $100 \mathrm{~Hz}$ stimulation increased the $\mathrm{p}-\mathrm{MLC}$ level, but pretreatment with the PKC $\varepsilon$ inhibitor peptide prevented this increase. $E$, Traces of EPPs during a $1 \mathrm{~s} 100 \mathrm{~Hz}$ train in control or PKC $\varepsilon$ inhibitor peptide-pretreated NMJs. Some endings (middle trace) exhibited depression and greater variability in EPP amplitude than the controls (top trace). Others exhibited cyclical total transmission failures, in this case to every other stimulus (bottom trace).

compared with $10 \mathrm{~Hz}$ stimulation without the inhibitor peptide (Fig. 7A). However, the inhibitor treatment reduced the intensity of p-MLC staining with $100 \mathrm{~Hz}$ stimulation to that seen with 10 $\mathrm{Hz}$ stimulation. (Fig. 8 B, C). These observations show that, during $100 \mathrm{~Hz}$ stimulation, PKC $\varepsilon$ is important in causing the phosphorylation of MLC. These results are summarized in the bar graph of Figure $8 D$. It is clear that both PMA and $100 \mathrm{~Hz}$ stimulation increase the phosphorylation level of MLC and that pretreatment with the PKC $\varepsilon$ inhibitor inhibited the increased phosphorylation in response to the $100 \mathrm{~Hz}$ stimulus. To deter- 
mine whether the PKC $\varepsilon$ inhibitor affected vesicle release, electrophysiological recordings were made (Fig. $8 E$ ). Interestingly, we found a heterogeneous response between endings when stimulated at $100 \mathrm{~Hz}$. One group (Fig. $8 \mathrm{E}$, bottom) exhibited cyclical total transmission failures, in this example failing with every other stimulus, whereas the other (Fig. $8 E$, middle) exhibited depression and greater variation in EPP amplitude than in control $100 \mathrm{~Hz}$ trains but no failures.

\section{Discussion}

We showed here that at adult mouse NMJs different modes of exocytosis and endocytosis are used for transmitter release, depending on the frequency of stimulation. At $10 \mathrm{~Hz}$, the speed of vesicle exocytosis and endocytosis appear balanced and the behavior of both transmitter and FM dye release were similar, suggesting full collapse exocytosis and subsequent endocytosis for vesicle replenishment. In contrast, at $100 \mathrm{~Hz}$, although transmitter continued to be released at sufficient levels to maintain effective transmission, less FM dye was released than predicted by the summed quantal content. This lower amount of dye loss suggests that the actual release mechanism may have changed with highfrequency stimulation. Applying folimycin during the $100 \mathrm{~Hz}$ stimulation resulted in much less transmitter being released than without the drug, indicating that, at $100 \mathrm{~Hz}$, vesicles are recycled and reused much more rapidly than at $10 \mathrm{~Hz}$. Also, the dynamin inhibitor, dynasore, greatly enhanced depression at $100 \mathrm{~Hz}$ with much less effect at $10 \mathrm{~Hz}$. Thus, dynamin-sensitive endocytosis contributed much more to maintaining effective transmission with $100 \mathrm{~Hz}$ than with $10 \mathrm{~Hz}$ stimulation. However, dynamin did not block transmission completely.

Blocking the MLCK pathway during high-frequency stimulation was previously shown to cause total transmission failures, presumably because of an inability to exocytose release competent vesicles at a rate needed to maintain transmission (PoloParada et al., 2005). Here, we provide direct evidence that stimulation at $100 \mathrm{~Hz}$, but not $10 \mathrm{~Hz}$, activates the MLCK pathway, as evidenced by increased phospho-MLC immunostaining in the nerve terminal. These observations lead us to conclude that a synaptic activity-dependent activation of MLCK is a key regulator for triggering a switch in the mode of vesicle cycling to facilitate recycling of vesicles during high-frequency stimulation. We also provide evidence that an elevated presynaptic calcium concentration and an upregulation of PKC activity, especially of $\mathrm{PKC} \varepsilon$, enhanced MLCK activation. The treatments that led to MLCK activation also caused a switch to the mode of vesicle exocytosis that lost less dye, even when junctions were stimulated at $10 \mathrm{~Hz}$. In addition, inhibition of PKC $\varepsilon$ caused total transmission failures at $100 \mathrm{~Hz}$, similar to those previously reported in 180 NCAM-deficient mice, which exhibit impaired MLCK activation (Polo-Parada et al., 2005).

\section{Characteristics of the mode of vesicle cycling in which less dye is lost}

Our folimycin data support the idea of rapid reuse of vesicles with high-, but not low-frequency stimulation. Such rapid reuse could be achieved by a kiss-and-run/transient fusion pore form of exocytosis (but see $\mathrm{Wu}$ and $\mathrm{Wu}, 2009$ ). Alternatively vesicles might undergo a rapid full collapse and rapid retrieval and be returned to the readily releasable pool. In either case, more FM dye would be retained in the terminal than predicted by the number of exocytosed vesicles based on the summed quantal content. Additional experiments, such as after the exocytosis of single vesicles labeled with nanoparticles or with a fluorescent $\mathrm{pH}$ reporter
(Zhang et al., 2009; Zhu et al., 2009), will be needed to definitively determine the type of vesicle fusion used during the rapid reuse we have observed.

In addition, we clearly showed that, even with $10 \mathrm{~Hz}$ stimulation, activation of the MLCK-myosin II pathway caused both a switch to a mode of exocytosis that lost less dye and an increase in the proportion of vesicles that were rapidly recycled. An enzymatic balance between MLCK and myosin light chain phosphatase regulates myosin II activity through phosphorylation of its light chain. MLCK in turn is activated by calcium and calmodulin $(\mathrm{CaM})$, whereas myosin light chain phosphatase is inhibited by a peptide, CPI-17, which is activated by PKC (Somlyo and Somlyo, 2003) (Fig. 6A). Thus, during high-frequency stimulation, it is likely that calcium influx would activate both the CaM and PKC signaling pathways, leading to the activation of MLCK and the inhibition of myosin phosphatase, respectively. The 180 isoform of NCAM, acting via a conserved intracellular domain, is also required for activation of the MLCK pathway by high-frequency stimulation (Polo-Parada et al., 2005). However, how NCAM enables activation of this pathway remains to be determined. Myosin II has also been shown to regulate catecholamine and neuropeptide release (Chan et al., 2005; Doreian et al., 2008, 2009; Berberian et al., 2009) as well as vesicle transport and fusion pore expansion in chromaffin cells (Neco et al., 2004, 2008). At the calyx of Held synapse, inhibition of MLCK was reported to increase the size of the fast releasing vesicle pool (Srinivasan et al., 2008). How the MLCK-myosin II pathway regulates the release of synaptic vesicles appears to vary among the systems studied, suggesting multiple roles of this pathway in different systems.

Although we have clearly demonstrated that the MLCK-myosin II pathway is required to maintain transmission with highfrequency stimulation, and that it enables the rapid reuse of vesicles and a form of exocytosis in which less FM dye is lost, determining the exact roles of myosin II in these processes will require additional studies. In addition to its role as a motor protein, myosin II has been shown to promote the severing of actin filaments and thus influence actin treadmilling in growth cones, as well as actin cytoskeleton dynamics in a variety of cell types (Lin et al., 1996; Medeiros et al., 2006; Vallee et al., 2009; VicenteManzanares et al., 2009; Rex et al., 2010). Dynasore can also cause remodeling of actin filaments by altering the association of dynamin and other molecules with the filaments (Mooren et al., 2009; Yamada et al., 2009). Thus, the effect of dynasore we observed might be attributable to inhibition of endocytosis and/or actin destabilization. Inhibition of actin polymerization can also slow catecholamine release from chromaffin cells (Doreian et al., 2008, 2009; Berberian et al., 2009). Clearly, much additional work will be required to show how myosin II activity and the regulation of actin dynamics affect exocytosis and the recycling of synaptic vesicles.

\section{Why are total transmission failures observed when the} MLCK-myosin II pathway is inhibited during high-frequency stimulation?

Adult mouse NMJs that lack all NCAM isoforms (Polo-Parada et al., 2001) or only the 180 isoform (Polo-Parada et al., 2004, 2005) exhibit total transmission failures when stimulated at $100 \mathrm{~Hz}$ or above. These were shown to be attributable to events downstream of $\mathrm{Ca}^{2+}$ influx into the terminal (Polo-Parada et al., 2001, 2004) and were prevented by activation of the MLCK pathway. In the present study, such failures were caused by inhibiting PKC $\varepsilon$, presumably upstream of the MLCK pathway. We currently do not 
have a clear explanation for the transmission failures. However, several observation made in the present study appear relevant.

One plausible hypothesis is that the failures are caused by blockage of active zone release sites by the exocytosed vesicles, which must be cleared to make room for subsequent vesicle docking. If exocytosis, and subsequent endocytosis, occur at different places, the blockage of endocytosis with dynasore should have only a gradual effect on exocytosis as recently endocytosed vesicles are reused. Thus, we expected to see a decline in EPP amplitude with a time course similar to that observed with folimycin treatment. However, dynasore caused an immediate, large enhancement of depression with $100 \mathrm{~Hz}$ stimulation, but very little with $10 \mathrm{~Hz}$ stimulation, suggesting that some of the recently exocytosed vesicles might be retrieved in a dynamin-dependent manner, freeing release sites for subsequent exocytosis. $\mathrm{Ca}^{2+}$ / calmodulin-initiated endocytosis was recently shown to facilitate vesicle mobilization by clearing fused vesicle membrane at release sites (Wu et al., 2009). Depression, caused by perturbation of calcium-dependent coupling of exocytosis and endocytosis, has also been suggested to result from a temporary reduction in new vesicles docking at release sites (Hosoi et al., 2009). These reports suggest that the physical availability of release sites might affect both exocytosis and endocytosis.

Another challenge of explaining the transmission failures is how the hundreds of active zones at rodent NMJs (Nishimune et al., 2004) could all fail simultaneously. At rat and frog NMJs, the probability of release for individual vesicles at each active zone is low (Wachman et al., 2004; Rowley et al., 2007) and many active zones contribute to the EPP. However, it was recently shown for mouse NMJs that, during high- but not low-frequency stimulation, preferred sites of exocytosis exist and that these are very close to sites of endocytosis (Gaffield et al., 2009a,b). If the probability of release at individual active zones changes during highfrequency stimulation and exocytosis only occurs at a limited number of preferred sites, temporary blockage of those sites would be more likely to produce total transmission failures. We did not observe failures with dynasore treatment. However, the persistence of a dynasore-insensitive form of transmission makes interpretation of this result difficult. Additional experiments will be needed to elucidate the mechanism underlying transmission failures.

In conclusion, this study shows that activation of the MLCKmyosin II pathway by high-frequency stimulation acts as a switch to trigger alterations in exocytosis and endocytosis, which are needed to maintain effective transmission. These include the rapid reuse of vesicles and an altered form of exocytosis that loses less FM dye. A full understanding of the precise mechanisms responsible for this altered dye loss will be explored in future experiments.

\section{References}

Alés E, Tabares L, Poyato JM, Valero V, Lindau M, Alvarez de Toledo G (1999) High calcium concentrations shift the mode of exocytosis to the kiss-and-run mechanism. Nat Cell Biol 1:40-44.

Berberian K, Torres AJ, Fang Q, Kisler K, Lindau M (2009) F-Actin and myosin II accelerate catecholamine release from chromaffin granules. J Neurosci 29:863-870.

Betz WJ, Mao F, Bewick GS (1992) Activity-dependent fluorescent staining and destaining of living vertebrate motor nerve terminals. J Neurosci 12:363-375.

Betz WJ, Mao F, Smith CB (1996) Imaging exocytosis and endocytosis. Curr Opin Neurobiol 6:365-371.

Chan SA, Polo-Parada L, Landmesser LT, Smith C (2005) Adrenal chromaffin cells exhibit impaired granule trafficking in NCAM knockout mice. J Neurophysiol 94:1037-1047.
Chung C, Barylko B, Leitz J, Liu X, Kavalali ET (2010) Acute dynamin inhibition dissects synaptic vesicle recycling pathways that drive spontaneous and evoked neurotransmission. J Neurosci 30:1363-1376.

Clayton EL, Anggono V, Smillie KJ, Chau N, Robinson PJ, Cousin MA (2009) The phospho-dependent dynamin-syndapin interaction triggers activity-dependent bulk endocytosis of synaptic vesicles. J Neurosci 29: 7706-7717.

Cousin MA, Robinson PJ (1999) Mechanisms of synaptic vesicle recycling illuminated by fluorescent dyes. J Neurochem 73:2227-2239.

Danglot L, Galli T (2007) What is the function of neuronal AP-3? Biol Cell 99:349-361.

David G, Barrett EF (2003) Mitochondrial $\mathrm{Ca}^{2+}$ uptake prevents desynchronization of quantal release and minimizes depletion during repetitive stimulation of mouse motor nerve terminals. J Physiol 548:425-438.

de Lange RP, de Roos AD, Borst JG (2003) Two modes of vesicle recycling in the rat calyx of Held. J Neurosci 23:10164-10173.

Doreian BW, Fulop TG, Smith CB (2008) Myosin II activation and actin reorganization regulate the mode of quantal exocytosis in mouse adrenal chromaffin cells. J Neurosci 28:4470-4478.

Doreian BW, Fulop TG, Meklemburg RL, Smith CB (2009) Cortical F-actin, the exocytic mode, and neuropeptide release in mouse chromaffin cells is regulated by myristoylated alanine-rich C-kinase substrate and myosin II. Mol Biol Cell 20:3142-3154.

Elmqvist D, Quastel DM (1965) Presynaptic action of hemicholinium at the neuromuscular junction J Physiol 177:463-482.

Ertunc M, Sara Y, Chung C, Atasoy D, Virmani T, Kavalali ET (2007) Fast synaptic vesicle reuse slows the rate of synaptic depression in the CA1 region of hippocampus. J Neurosci 27:341-354.

Fulop T, Radabaugh S, Smith C (2005) Activity-dependent differential transmitter release in mouse adrenal chromaffin cells. J Neurosci 25: $7324-7332$

Gaffield MA, Betz WJ (2006) Imaging synaptic vesicle exocytosis and endocytosis with FM dyes. Nat Protoc 1:2916-2921.

Gaffield MA, Tabares L, Betz WJ (2009a) The spatial pattern of exocytosis and post-exocytic mobility of synaptopHluorin in mouse motor nerve terminals. J Physiol 587:1187-1200.

Gaffield MA, Tabares L, Betz WJ (2009b) Preferred sites of exocytosis and endocytosis colocalize during high- but not lower-frequency stimulation in mouse motor nerve terminals. J Neurosci 29:15308-15316.

Gandhi SP, Stevens CF (2003) Three modes of synaptic vesicular recycling revealed by single-vesicle imaging. Nature 423:607-613.

Gorassini M, Eken T, Bennett DJ, Kiehn O, Hultborn H (2000) Activity of hindlimb motor units during locomotion in the conscious rat. J Neurophysiol 83:2002-2011.

Harata NC, Choi S, Pyle JL, Aravanis AM, Tsien RW (2006a) Frequencydependent kinetics and prevalence of kiss-and-run and reuse at hippocampal synapses studied with novel quenching methods. Neuron 49: 243-256.

Harata NC, Aravanis AM, Tsien RW (2006b) Kiss-and-run and fullcollapse fusion as modes of exo-endocytosis in neurosecretion. J Neurochem 97:1546-1570.

Hata K, Polo-Parada L, Landmesser LT (2007) Selective targeting of different neural cell adhesion molecule isoforms during motoneuron myotube synapse formation in culture and the switch from an immature to mature form of synaptic vesicle cycling. J Neurosci 27:14481-14493.

He L, Wu LG (2007) The debate on the kiss-and-run fusion at synapses. Trends Neurosci 30:447-455.

Heuser JE, Reese TS (1973) Evidence for recycling of synaptic vesicle membrane during transmitter release at the frog neuromuscular junction. J Cell Biol 57:315-344.

Hosoi N, Holt M, Sakaba T (2009) Calcium dependence of exo- and endocytotic coupling at a glutamatergic synapse. Neuron 63:216-229.

Jockusch WJ, Praefcke GJ, McMahon HT, Lagnado L (2005) Clathrindependent and clathrin-independent retrieval of synaptic vesicles in retinal bipolar cells. Neuron 46:869-878.

Klingauf J, Kavalali ET, Tsien RW (1998) Kinetics and regulation of fast endocytosis at hippocampal synapses. Nature 394:581-585.

Klyachko VA, Jackson MB (2002) Capacitance steps and fusion pores of small and large-dense-core vesicles in nerve terminals. Nature 418:89-92.

Koenig JH, Ikeda K (1996) Synaptic vesicles have two distinct recycling pathways. J Cell Biol 135:797-808.

Koide H, Ogita K, Kikkawa U, Nishizuka Y (1992) Isolation and character- 
ization of the epsilon subspecies of protein kinase $\mathrm{C}$ from rat brain. Proc Natl Acad Sci U S A 89:1149-1153.

Lin CH, Espreafico EM, Mooseker MS, Forscher P (1996) Myosin drives retrograde F-actin flow in neuronal growth cones. Neuron 16:769-782.

Lu W, Ma H, Sheng ZH, Mochida S (2009) Dynamin and activity regulate synaptic vesicle recycling in sympathetic neurons. J Biol Chem 284: 1930-1937.

Maeno-Hikichi Y, Chang S, Matsumura K, Lai M, Lin H, Nakagawa N, Kuroda S, Zhang JF (2003) A PKC $\varepsilon$-ENH-channel complex specifically modulates N-type $\mathrm{Ca}^{2+}$ channels. Nat Neurosci 6:468-475.

Medeiros NA, Burnette DT, Forscher P (2006) Myosin II functions in actinbundle turnover in neuronal growth cones. Nat Cell Biol 8:215-226.

Miller TM, Heuser JE (1984) Endocytosis of synaptic vesicle membrane at the frog neuromuscular junction. J Cell Biol 98:685-698.

Mooren OL, Kotova TI, Moore AJ, Schafer DA (2009) Dynamin2 GTPase and cortactin remodel actin filaments. J Biol Chem 284:23995-24005.

Neco P, Giner D, Viniegra S, Borges R, Villarroel A, Gutiérrez LM (2004) New roles of myosin II during vesicle transport and fusion in chromaffin cells. J Biol Chem 279:27450-27457.

Neco P, Fernández-Peruchena C, Navas S, Gutiérrez LM, de Toledo GA, Alés E (2008) Myosin II contributes to fusion pore expansion during exocytosis. J Biol Chem 283:10949-10957.

Neher E, Marty A (1982) Discrete changes of cell membrane capacitance observed under conditions of enhanced secretion in bovine adrenal chromaffin cells. Proc Natl Acad Sci U S A 79:6712-6716.

Nishimune H, Sanes JR, Carlson SS (2004) A synaptic laminin-calcium channel interaction organizes active zones in motor nerve terminals. $\mathrm{Na}-$ ture 432:580-587.

Ono Y, Fujii T, Ogita K, Kikkawa U, Igarashi K, Nishizuka Y (1988) The structure, expression, and properties of additional members of the protein kinase C family. J Biol Chem 263:6927-6932.

Polo-Parada L, Bose CM, Landmesser LT (2001) Alterations in transmission, vesicle dynamics, and transmitter release machinery at NCAMdeficient neuromuscular junctions. Neuron 32:815-828.

Polo-Parada L, Bose CM, Plattner F, Landmesser LT (2004) Distinct roles of different neural cell adhesion molecule (NCAM) isoforms in synaptic maturation revealed by analysis of NCAM $180 \mathrm{kDa}$ isoform-deficient mice. J Neurosci 24:1852-1864.

Polo-Parada L, Plattner F, Bose C, Landmesser LT (2005) NCAM 180 acting via a conserved C-terminal domain and MLCK is essential for effective transmission with repetitive stimulation. Neuron 46:917-931.

Prekeris R, Mayhew MW, Cooper JB, Terrian DM (1996) Identification and localization of an actin-binding motif that is unique to the epsilon isoform of protein kinase $\mathrm{C}$ and participates in the regulation of synaptic function. J Cell Biol 132:77-90.

Reid B, Slater CR, Bewick GS (1999) Synaptic vesicle dynamics in rat fast and slow motor nerve terminals. J Neurosci 19:2511-2521.

Rex CS, Gavin CF, Rubio MD, Kramar EA, Chen LY, Jia Y, Huganir RL, Muzyczka N, Gall CM, Miller CA, Lynch G, Rumbaugh G (2010) Myosin IIb regulates actin dynamics during synaptic plasticity and memory formation. Neuron 67:603-617.

Richards DA, Guatimosim C, Betz WJ (2000) Two endocytic recycling routes selectively fill two vesicle pools in frog motor nerve terminals. Neuron 27:551-559.

Richards DA, Guatimosim C, Rizzoli SO, Betz WJ (2003) Synaptic vesicle pools at the frog neuromuscular junction. Neuron 39:529-541.

Rizzoli SO, Betz WJ (2005) Synaptic vesicle pools. Nat Rev Neurosci 6:57-69.

Rizzoli SO, Jahn R (2007) Kiss-and-run, collapse and "readily retrievable" vesicles. Traffic 8:1137-1144

Rowley KL, Mantilla CB, Ermilov LG, Sieck GC (2007) Synaptic vesicle distribution and release at rat diaphragm neuromuscular junctions. J Neurophysiol 98:478-487.

Royle SJ, Lagnado L (2003) Endocytosis at the synaptic terminal. J Physiol 553:345-355.
Ryan TA (2001) Presynaptic imaging techniques. Curr Opin Neurobiol 11:544-549.

Ryan TA, Smith SJ, Reuter H (1996) The timing of synaptic vesicle endocytosis. Proc Natl Acad Sci U S A 93:5567-5571.

Saitoh N, Hori T, Takahashi T (2001) Activation of the epsilon isoform of protein kinase $\mathrm{C}$ in the mammalian nerve terminal. Proc Natl Acad Sci U S A 98:14017-14021.

Scheuber A, Rudge R, Danglot L, Raposo G, Binz T, Poncer JC, Galli T (2006) Loss of AP-3 function affects spontaneous and evoked release at hippocampal mossy fiber synapses. Proc Natl Acad Sci U S A 103:16562-16567.

Schofield GG, Marshall IG (1980) Neuromuscular transmission in the athymic nude mouse. J Neurol Sci 48:21-34.

Sieburth D, Madison JM, Kaplan JM (2007) PKC-1 regulates secretion of neuropeptides. Nat Neurosci 10:49-57.

Somlyo AP, Somlyo AV (2003) $\mathrm{Ca}^{2+}$ sensitivity of smooth muscle and nonmuscle myosin II: modulated by $\mathrm{G}$ proteins, kinases, and myosin phosphatase. Physiol Rev 83:1325-1358.

Srinivasan G, Kim JH, von Gersdorff H (2008) The pool of fast releasing vesicles is augmented by myosin light chain kinase inhibition at the calyx of Held synapse. J Neurophysiol 99:1810-1824.

Stevens CF, Williams JH (2000) "Kiss and run" exocytosis at hippocampal synapses. Proc Natl Acad Sci U S A 97:12828-12833.

Tsai CC, Lin CL, Wang TL, Chou AC, Chou MY, Lee CH, Peng IW, Liao JH, Chen YT, Pan CY (2009) Dynasore inhibits rapid endocytosis in bovine chromaffin cells. Am J Physiol Cell Physiol 297:C397-C406.

Vallee RB, Seale GE, Tsai JW (2009) Emerging roles for myosin II and cytoplasmic dynein in migrating neurons and growth cones. Trends Cell Biol 19:347-355.

Vicente-Manzanares M, Ma X, Adelstein RS, Horwitz AR (2009) Nonmuscle myosin II takes centre stage in cell adhesion and migration. Nat Rev Mol Cell Biol 10:778-790.

Voglmaier SM, Edwards RH (2007) Do different endocytic pathways make different synaptic vesicles? Curr Opin Neurobiol 17:374-380.

Voglmaier SM, Kam K, Yang H, Fortin DL, Hua Z, Nicoll RA, Edwards RH (2006) Distinct endocytic pathways control the rate and extent of synaptic vesicle protein recycling. Neuron 51:71-84.

Wachman ES, Poage RE, Stiles JR, Farkas DL, Meriney SD (2004) Spatial distribution of calcium entry evoked by single action potentials within the presynaptic active zone. J Neurosci 24:2877-2885.

Wang CT, Lu JC, Bai J, Chang PY, Martin TF, Chapman ER, Jackson MB (2003) Different domains of synaptotagmin control the choice between kiss-and-run and full fusion. Nature 424:943-947.

Wetsel WC, Khan WA, Merchenthaler I, Rivera H, Halpern AE, Phung HM, Negro-Vilar A, Hannun YA (1992) Tissue and cellular distribution of the extended family of protein kinase C isoenzymes. J Cell Biol 117:121-133.

Wu XS, Wu LG (2009) Rapid endocytosis does not recycle vesicles within the readily releasable pool. J Neurosci 29:11038-11042.

Wu XS, McNeil BD, Xu J, Fan J, Xue L, Melicoff E, Adachi R, Bai L, Wu LG (2009) $\mathrm{Ca}^{2+}$ and calmodulin initiate all forms of endocytosis during depolarization at a nerve terminal. Nat Neurosci 12:1003-1010.

Xu J, McNeil B, Wu W, Nees D, Bai L, Wu LG (2008) GTP-independent rapid and slow endocytosis at a central synapse. Nat Neurosci 11:45-53.

Yamada H, Abe T, Li SA, Masuoka Y, Isoda M, Watanabe M, Nasu Y, Kumon H, Asai A, Takei K (2009) Dynasore, a dynamin inhibitor, suppresses lamellipodia formation and cancer cell invasion by destabilizing actin filaments. Biochem Biophys Res Commun 390:1142-1148.

Zakharenko S, Chang S, O’Donoghue M, Popov SV (1999) Neurotransmitter secretion along growing nerve processes: comparison with synaptic vesicle exocytosis. J Cell Biol 144:507-518.

Zhang Q, Li Y, Tsien RW (2009) The dynamic control of kiss-and-run and vesicular reuse probed with single nanoparticles. Science 323:1448-1453.

Zhu Y, Xu J, Heinemann SF (2009) Two pathways of synaptic vesicle retrieval revealed by single-vesicle imaging. Neuron 61:397-411. 